\title{
VALVULOTOMY FOR PULMONARY VALVULAR STENOSIS
}

\author{
BY \\ R. C. BROCK and MAURICE CAMPBELL \\ From the Thoracic Surgical Unit and the Cardiac Department, Guy's Hospital \\ Received May 27, 1950
}

An earlier paper, reporting 3 successful cases (Brock, 1948), showed the feasibility of valvulotomy for the relief of pulmonary valvular stenosis. The present paper deals with our clinical and operative experience in 33 cases-a number large enough to allow certain conclusions to be drawn.

Of the 33 patients submitted to operation, 18 had pure pulmonary stenosis, by which we mean pulmonary valvular stenosis with a closed interventricular septum, regardless of the patency or potential patency of the foramen ovale, and in 7 this was confirmed by necropsy (see Table I); all but 3 probably had a patent foramen ovale and in 6 this was proved by necropsy. In the other 15 (see Table II) valvular stenosis was thought to be part of a Fallot's tetralogy and in 3 this was confirmed by necropsy.

Increasing experience in the diagnosis and surgical treatment of pulmonary stenosis has led us from a grave mortality of just over 50 per cent in the first 11 patients, most of whom were unlikely to live long as they had very large hearts and often congestive failure, to a mortality of 18 per cent in the remaining 22 , these including many younger patients in whom the stenosis had not yet caused such serious changes.

\section{Pure Pulmonary Valvular Stenosis}

The clinical and pathological features of pulmonary stenosis with a closed ventricular septum have recently been presented by Allanby and Campbell (1949) and also by Selzer, et al. (1949), but as the former dealt mainly with cases where the diagnosis was proved post-mortem, something more must be said about the less advanced cases. Pure pulmonary stenosis is nearly always valvular and may lead to very varying effects, according to its severity and to the sealing or potential patency of the foramen ovale. At first the symptoms may be slight and the patient will develop normally, so that attention may only be drawn to the heart by the finding of physical signs.

There are four main possibilities. (1) The stenosis may not be severe and the patient may be only slightly limited on exertion; he may lead an active life and reach a good age without developing cyanosis. It may then be difficult, if not impossible, to tell during life if the foramen ovale is sealed or not; several patients in this series were acyanotic in childhood and appeared to belong to this group, but later became cyanotic, see (3); others, e.g. Case G.G. (Allanby and Campbell, 1949) who lived for 57 years, remain in this group through life. Many others have been seen who are at present in this group and in some of them the diagnosis has been confirmed by cardiac catheterization (see Table V); and Dow et al. (1950) described eight such patients where the symptoms were only slight.

(2) The stenosis may be more severe with a foramen ovale that is anatomically sealed. Here the pressure will rise on the right side of the heart, and with no alternative route for the blood the right ventricle will hypertrophy greatly in trying to overcome the obstruction; but no right to left shunt can develop and there will be no central cyanosis, though later some peripheral cyanosis may 
TABLE I

Cases of pure Pulmonary Valvular Stenosis who have had Pulmonary Valvulotomy (18 cases).*

\begin{tabular}{|c|c|c|c|c|c|c|c|c|c|c|c|c|}
\hline 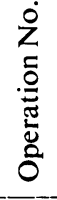 & 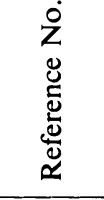 & 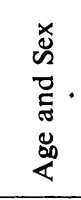 & 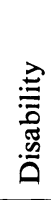 & 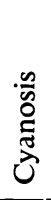 & 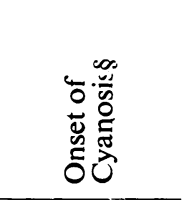 & 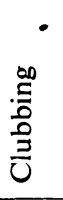 & 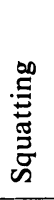 & $\underset{5}{\stackrel{5}{0}}$ & 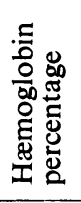 & 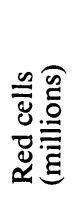 & 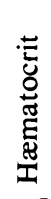 & 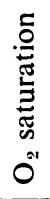 \\
\hline & & & & & \multicolumn{8}{|c|}{ With Defect of the Atrial Septum (P.F.O.) } \\
\hline 1 & $\mathrm{PO} 31+$ & $21 \mathrm{~F}$ & $4 \ddagger$ & 4 & $7(20) \mathrm{yr}$. & 0 & $\mathrm{~N}$ & $\mathrm{~L}$ & 109 & $5 \cdot 5$ & 69 & 91 \\
\hline 5 & $\mathrm{H} 117 \dagger$ & $29 \mathrm{~F}$ & $4 t$ & 3 & $18 \mathrm{yr}$. & 4 & $\mathrm{~N}$ & $\mathrm{~L}$ & 157 & $9 \cdot 4$ & 80 & 77 \\
\hline 7 & $0207 \dagger$ & $26 \mathrm{~F}$ & 4 & 3 & $18 \mathrm{yr}$. & 3 & $\mathrm{~N}$ & $\mathrm{~L}$ & 12 & $7 \cdot 8$ & - & 69 \\
\hline 9 & $0124 \dagger$ & $22 \mathrm{M}$ & 4 & 2 & 1 (10) yr. & 4 & $\mathrm{~N}$ & $\overline{\mathrm{L}}$ & 11 & 9. & 64 & 73 \\
\hline 11 & 0041 & $9 \mathrm{~F}$ & $4 \ddagger$ & 4 & 4 yr. & 3 & $\mathrm{~N}$ & 1 & 15 & 8. & 77 & 52 \\
\hline 19 & G.H. & $20 \mathrm{~F}$ & $4 \%$ & 4 & В (12-18 yr.) & 4 & $\mathrm{~N}$ & L & 13 & $7 \cdot 3$ & - & - \\
\hline 23 & H115 & $11 \mathrm{~F}$ & 2 & 3 & $17 \mathrm{mo}$. & 4 & $\mathbf{S}$ & $\mathrm{L}$ & 138 & $7 \cdot 0$ & 62 & 68 \\
\hline \multicolumn{13}{|c|}{ With Both Septa Closed } \\
\hline 8 & P212 & $9 \mathrm{~F}$ & 3 & 0 & - & 0 & $\mathrm{~N}$ & $\mathrm{~L}$ & 94 & $4 \cdot 8$ & - & - \\
\hline 27 & C.E. & $8 \mathrm{~F}$ & 3 & 0 & - & 0 & $\mathrm{~N}$ & $\mathrm{~L}$ & 88 & $4 \cdot c$ & - & 96 \\
\hline 30 & P247 & $12 \mathrm{M}$ & 1 & 0 & - & 0 & $\mathrm{~N}$ & $\overline{\mathrm{L}}$ & 85 & $4 \cdot 6$ & 39 & 97 \\
\hline \multicolumn{13}{|c|}{ With extreme rotation and other complications } \\
\hline 22 & 0212 & $12 \mathrm{~F}$ & 3 & $3-$ & B & 4 & (S) & $\mathbf{R}$ & 124 & $7 \cdot 3$ & 60 & 73 \\
\hline
\end{tabular}

* The 7 cases operated on in America have not been included in the Table.

$\uparrow$ These cases have been fully reported by Allanby and Campbell (1949).

$\ddagger$ In all these patients the disability had been less-sometimes much less.

$\S$ Where a second figure is given in brackets it indicates the age at which cyanosis became worse.

TABLE II

Cases of Fallot's Tetralogy with Valvular Stenosis who have had Pulmonary Valvulotomy (15 cases)

\begin{tabular}{|c|c|c|c|c|c|c|c|c|c|c|c|c|}
\hline 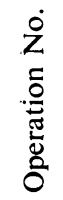 & 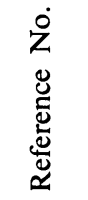 & 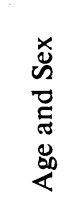 & 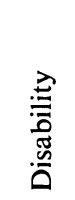 & 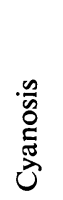 & 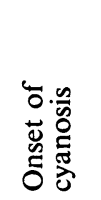 & 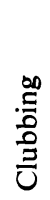 & 品 & $\frac{\pi}{2}$ & 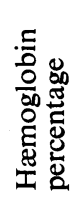 & 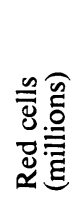 & 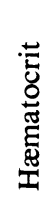 & 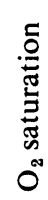 \\
\hline $\begin{array}{r}2 \\
3 \\
4 \\
6 \\
10 \\
20 \\
21 \\
24 \\
25 \\
26 \\
28 \\
29 \\
31 \\
32 \\
33\end{array}$ & $\begin{array}{l}\text { P079 } \\
\text { H107 } \\
\text { H109 } \\
\text { H121 } \\
0153 \\
0071 \\
0373 \\
0290 \\
\text { P127 } \\
\text { CB03 } \\
\text { CB12 } \\
\text { P072 } \\
\text { U.P. } \\
\text { O058 } \\
\text { D.C. }\end{array}$ & $\begin{array}{c}18 \mathrm{~F} \\
11 \mathrm{~F} \\
23 \mathrm{~F} \\
24 \mathrm{~F} \\
21 \mathrm{M} \\
13 \mathrm{M} \\
7 \mathrm{~F} \\
12 \mathrm{M} \\
9 \mathrm{M} \\
3 \mathrm{~F} \\
8 \mathrm{~F} \\
17 \mathrm{~F} \\
9 \mathrm{M} \\
18 \mathrm{~F} \\
5 \mathrm{M}\end{array}$ & $\begin{array}{c}3 \\
4 \\
4 \\
3 \\
2 \\
3 \\
2+ \\
3 \\
3 \\
3 \\
2-3 \\
3 \\
3 \\
2+ \\
3\end{array}$ & $\begin{array}{l}3 \\
4 \\
2 \\
3 \\
4 \\
3 \\
3- \\
2 \\
2 \\
2 \\
3 \\
2 \\
4 \\
2 \\
3\end{array}$ & $\begin{array}{l}\mathrm{B}^{*} \\
6 \mathrm{mo} . \\
\mathrm{B} \\
2 \mathrm{yr} . \\
\mathrm{B} . \\
2 \mathrm{yr} . \\
9 \mathrm{mo} . \\
5 \mathrm{yr} . \\
18 \mathrm{mo} . \\
\mathrm{B} \\
6 \mathrm{mo} . \\
1 \mathrm{yr} . \\
\mathrm{B} \\
2 \mathrm{yr} . \\
\mathrm{B} .\end{array}$ & $\begin{array}{l}3 \\
4 \\
3 \\
3 \\
(4) \\
3 \\
4 \\
1 \\
4 \\
2 \\
3 \\
(4) \\
4 \\
4 \\
3\end{array}$ & $\begin{array}{l}\mathbf{S} \\
\mathbf{S} \\
\mathbf{S} \\
\mathbf{N} \\
\mathbf{S} \\
\mathbf{S} \\
\mathbf{S} \\
\mathbf{S} \\
\mathbf{S} \\
\mathbf{S} \\
\mathbf{S} \\
\mathbf{S} \\
\mathrm{N} \\
5\end{array}$ & $\begin{array}{c}\text { L } \\
\text { R } \\
\text { R } \\
\text { L } \\
\text { R } \\
\text { R } \\
\text { L } \\
\text { L } \\
\text { L } \\
\text { ? } \\
\text { L } \\
\text { R } \\
\text { L } \\
\text { L } \\
\text { L }\end{array}$ & $\begin{array}{l}129 \\
156 \\
128 \\
152 \\
180 \\
121 \\
128 \\
94 \\
122 \\
109 \\
142 \\
105 \\
120 \\
136\end{array}$ & $\begin{array}{l}7.4 \\
8.7 \\
6.5 \\
8.9 \\
8.6 \\
6.0 \\
6.4 \\
5.9 \\
6.4 \\
7.8 \\
7.5 \\
5.6 \\
5.5 \\
6.8\end{array}$ & $\begin{array}{l}77 \\
56 \\
82 \\
82 \\
55 \\
59 \\
45 \\
52 \\
58 \\
51 \\
60 \\
\end{array}$ & $\begin{array}{l}\frac{88}{-} \\
- \\
-\end{array}$ \\
\hline
\end{tabular}

* B indicates from birth. 
complicate the picture. Right ventricular failure is a serious danger. Case 8 is a good example, as a very large heart (Fig. 1) and severe disability and failure had developed by the age of 9 years. Case 27 (probably) and Case 30 (almost certainly) are other examples at a much earlier stage, with the heart size still normal (Fig. 2).

(3) The pulmonary stenosis may be or may become severe and the foramen ovale may not be sealed, so that as the obstruction raises the pressure on the right side, a right to left interatrial shunt develops. This may occur only after some years, especially in early adult life and then a patient who has been acyanotic and relatively fit becomes more disabled and cyanotic; in such cases the

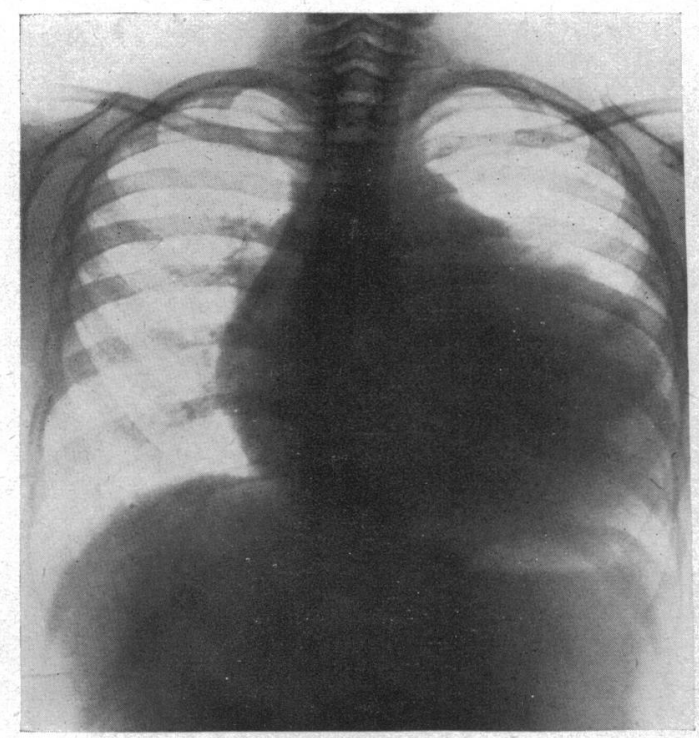

Fig. 1.-Teleradiogram from Case 8 with pure pulmonary stenosis, showing a very large heart (c.t.r. 70 , m.t.d. $15 / 21 \mathrm{~cm}$.) that had developed by the age of 9 years. There is extreme oligœmia of the lung fields.

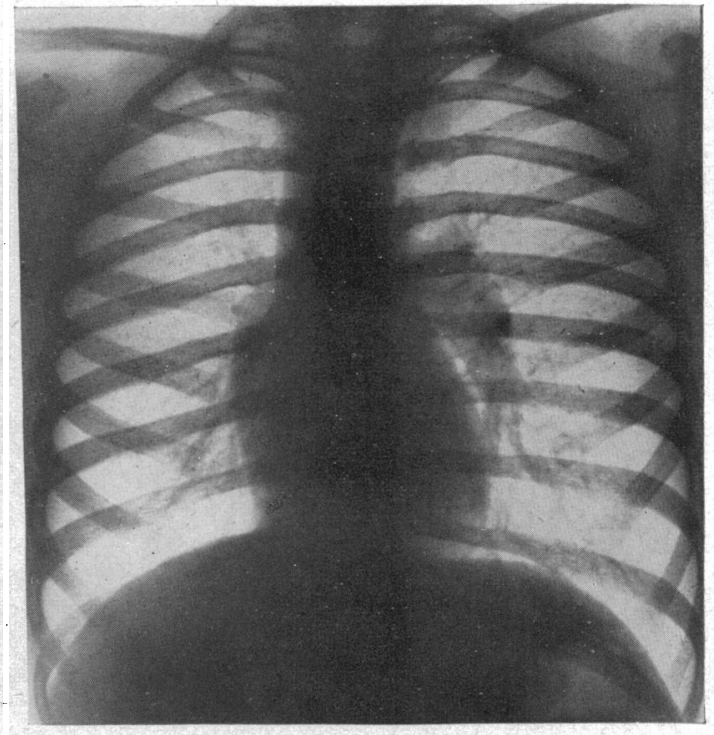

FIG. 2.-Teleradiogram from Case 30, with pure pulmonary stenosis, showing a heart that is not enlarged (c.t.r. 41 , m.t.d. $8 \cdot 8 / 21 \cdot 8$ ), where few symptoms had developed although the pressure in the right ventricle was extremely high. In spite of the unusual dilatation of the pulmonary trunk and left pulmonary artery, the lung fields are oligæmic.

subsequent deterioration is generally rapid, the heart may increase in size rapidly (Fig. 3) and rightsided congestive heart failure may follow quickly. Cases 1,5 , and 7 are good examples.

(4) The stenosis may be so severe that the right to left shunt develops early and then the patients are cyanotic from infancy and resemble those with Fallot's tetralogy. Cases 22 and 23 are good examples.

Cases 9, 11, and 19 are border-line between this and the preceding group, as though there was some cyanosis from infancy it became much worse in the late teens, with increasing disability. Case 23 (and Case 9) were, in fact, diagnosed Fallot's tetralogy and the correct diagnosis was made by cardiac catheterization.

Case 22 is included here but the full diagnosis is uncertain. A general picture like Fallot's tetralogy with left ventricular preponderance in the electrocardiogram and left ventricular hypertrophy on radioscopy led to a confident diagnosis of tricuspid atresia. Catheterization did not exclude this as there was a double superior vena cava and a defect of the atrial septum and the right ventricle was not entered, but angiocardiography suggested pulmonary stenosis. At operation there was no doubt about the presence of a large right ventricle and pulmonary valvular stenosis with extreme rotation of the heart, or about her improvement as a result of the pulmonary valvulotomy, but we do not feel sure of what other abnormalities may be present, especially as she had a right-sided aortic arch which has not been found with any proved case of pure pulmonary stenosis. 


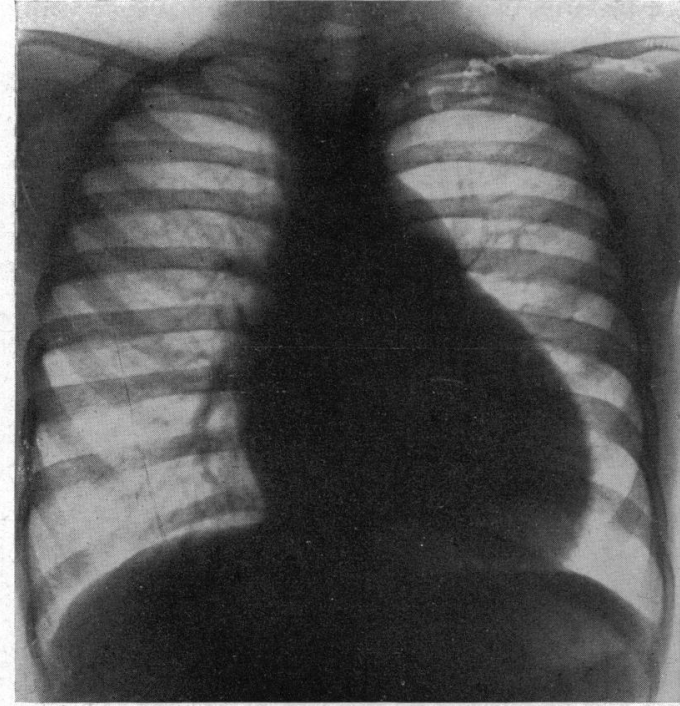

A

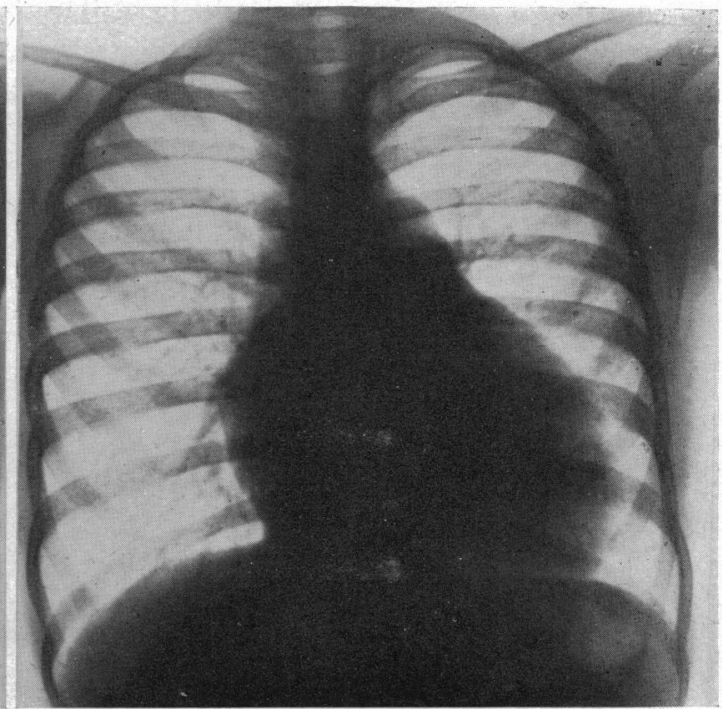

B

FIG. 3.-Rapid increase in size of the heart in pure pulmonary stenosis. In 11 months the cardiothoracic ratio had increased from $58.5(12 / 20.5)$ to $63.5(13.25 / 20.75)$, when the patient was becoming much worse and the cyanosis extreme. Death occurred during the induction of anæsthesia, and earlier operation might have been much less dangerous. The lung fields are very oligæmic with poorly developed pulmonary arteries. Case 11.
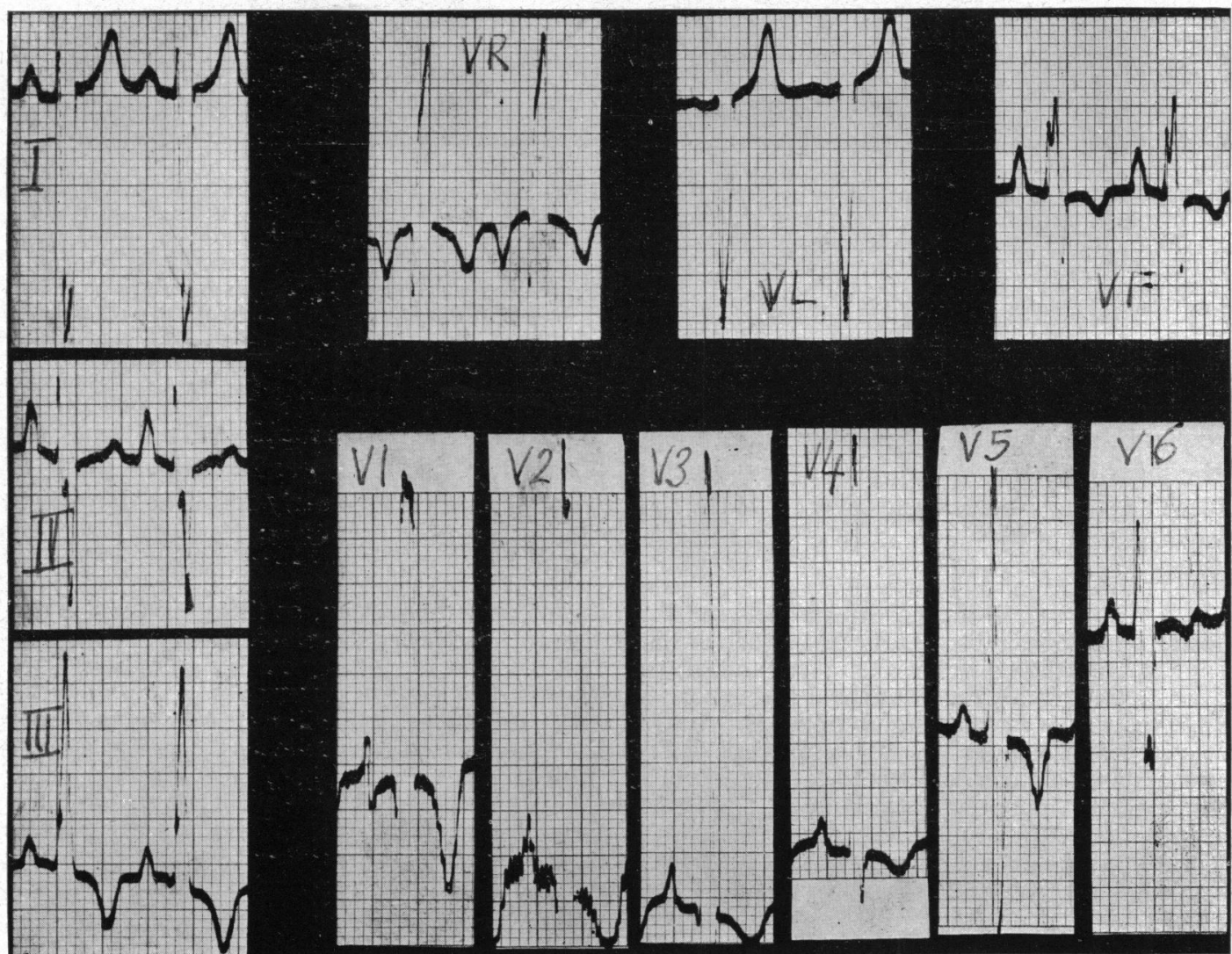

FIG. 4.-Standard and unipolar leads from Case 11, with pure pulmonary stenosis and gross right ventricular hypertrophy, confirmed post-mortem.: A large $\mathbf{R}$ wave with $\mathrm{T}$ inversion persists across to V5. There is notching and widening of QRS. The $P$ wave is very large and pointed in leads II and VF, and inverted in VR. 
The seven cases operated on at Baltimore (Cases 12-18) have not been included in Tables I and II as they are only considered here from the operative point of view. All were thought to have pure pulmonary stenosis. All were thought, after catheterization or angiocardiography, to have a defect of the atrial septum, most likely a patent foramen ovale; though in Case 16 the right to left shunt may only have been present after angiocardiography as the arterial $\mathrm{O}_{2}$ was 94 per cent and he was the only patient who was not cyanotic.

Most of these cases belong to groups 3 and 4 because so far it is mainly the cyanotic patients who have been submitted to operation. The proportion in the different groups here are not representative and, indeed, the acyanotic cases are much more common than would be judged from these figures.

The cyanotic cases bear a general resemblance to those with Fallot's tetralogy, but the cyanosis may have started later and the polycythæmia and clubbing of the fingers may be less than expected for the degree of cyanosis, because this is of more recent onset and may be partly peripheral. Peripheral cyanosis forms a more prominent part of the later clinical picture because the greatly reduced cardiac output leads to a low oxygen saturation in the venous blood.

The systolic murmur and thrill in the pulmonary area are generally more obvious than in Fallot's tetralogy and their maximum site tends to be rather higher. As the condition worsens and the pulmonary blood flow decreases they may become less obvious. Right-sided heart failure is increasingly the danger. This may be entirely due to the condition of the heart muscle but sometimes it is precipitated by the stenosis becoming worse from added inflammation or from progressive fibrosis caused by the stress.

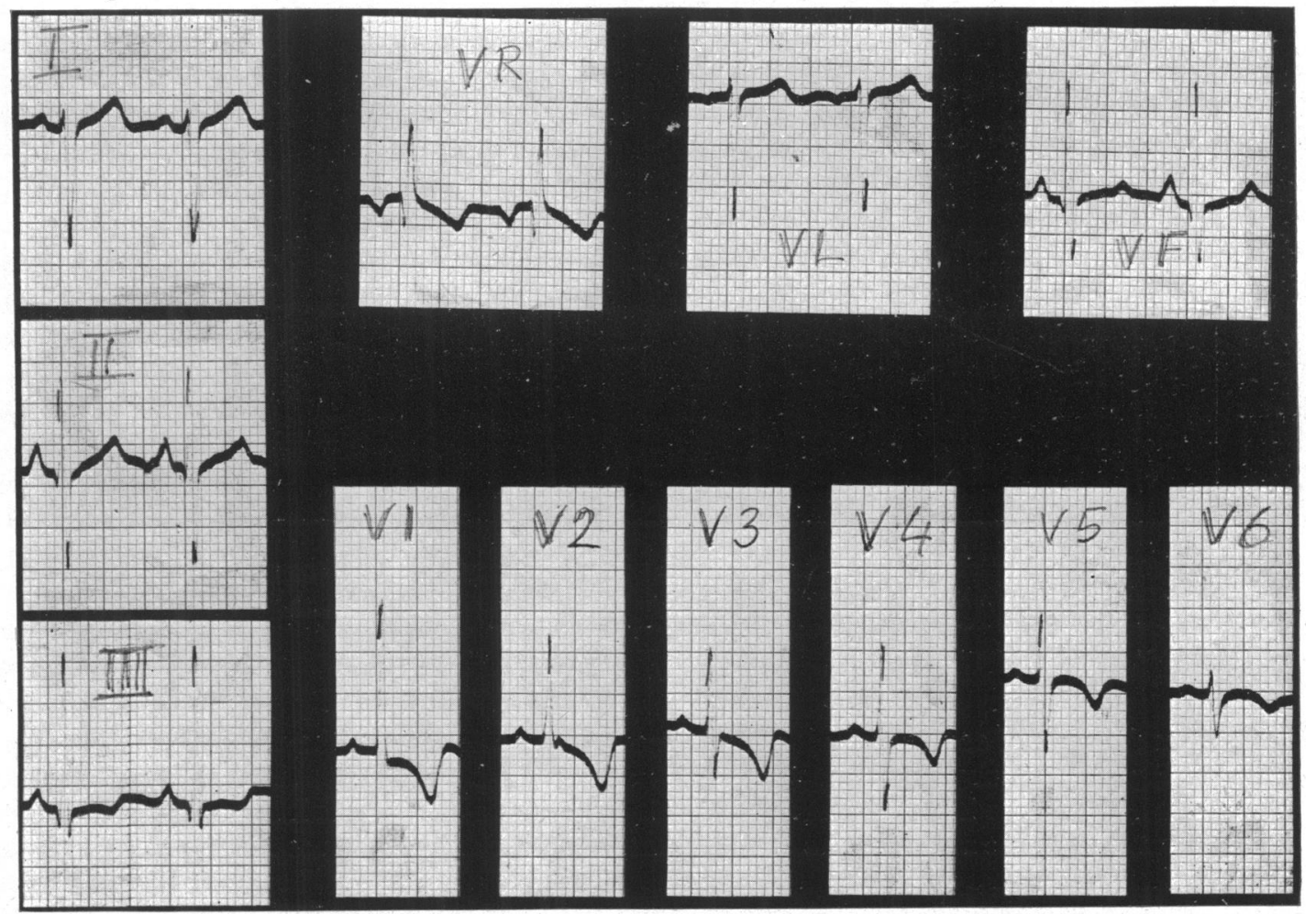

Fig. 5.-Standard and unipolar leads from Case 30 with pure pulmonary stenosis. Although the patient had little disability or enlargement of the heart, there is a large $R$ without $S$ in $V 1$ and $V 2$ and $R$ is larger or equal to $S$ in V3 to V5; deep $T$ inversion persists from V1 to V6, though it is becoming less in V5 and V6. Standardization $2 \mathrm{C}$ of V1-V6, $1 \mathrm{MV}=0.5 \mathrm{~cm}$. 
A history of squatting or the presence of a right-sided aortic arch is rare. We have not seen either of these in any proved instance, though Case 23, who probably had pure pulmonary stenosis, squatted at times (she may have learnt it in a home where several children squatted) and Case 22, a very unusual example in other ways, had a right-sided aortic arch.

The electrocardiogram of pure pulmonary stenosis. Right ventricular preponderance and the large pointed P II in the electrocardiogram are even more striking than in Fallot's tetralogy. In the standard leads T III and T II are more often inverted and in the unipolar chest leads large $R$ waves with deep $T$ inversion may spread across from $V 1$ to $V 5$ or even $V 6$. The absence of

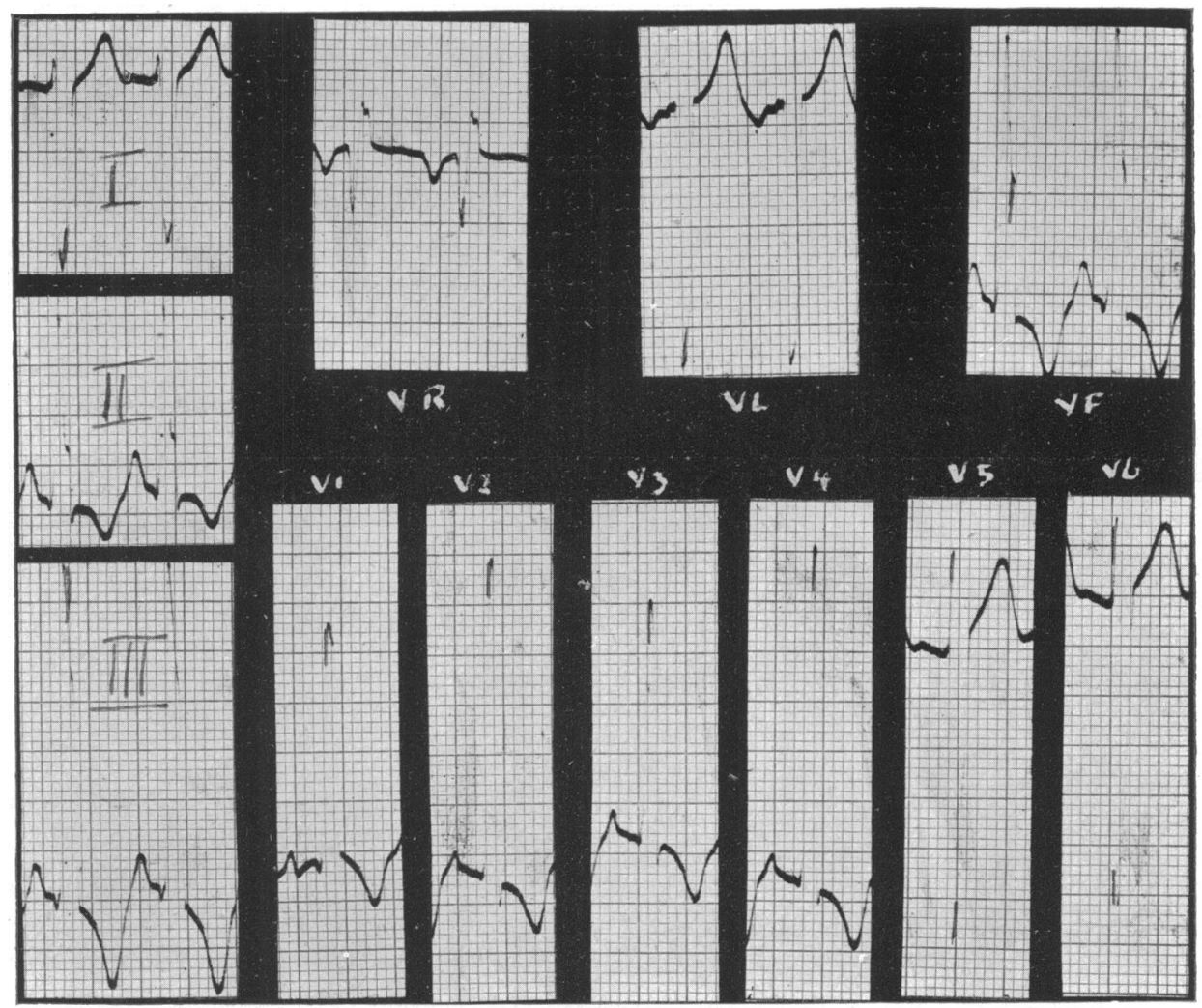

FIG. 6.-Standard and unipolar leads from Case 0328 with pure pulmonary stenosis. The gross right axis deviation with T II and T III inversion is the pattern suggestive of pure pulmonary stenosis. A very large $R$ wave with $T$ inversion persists from V1 to V4 with a sudden transition to $S$ and an upright $T$ in V5 and V6. Standardization of $\mathrm{V} 1$ to $\mathrm{V} 6,1 \mathrm{MV}=0.5 \mathrm{~cm}$.

these features does not of course exclude pure pulmonary stenosis because they take time to develop. In Case 8 (Fig. 11, Allanby and Campbell, 1949) and in Case 11 (Fig. 4) these changes are well seen in patients with large hearts and much disability; they are nearly as obvious in Case 30 (Fig. 5), where there was no cyanosis or cardiac enlargement, but a very high pressure in the right ventricle. Fig. 6 is similar, but with a sudden transition point between V 4 and V 5. Sometimes at an earlier stage of the disease these changes are much less. In Fig. 7 they are present only in $\mathrm{V} 1$ and $\mathrm{V} 2$ and in Case 0091 they were not very striking even in V 1: both these patients showed more disability than Case 30, and the pressure in the right ventricle was high, though not as high (see Table VI). 


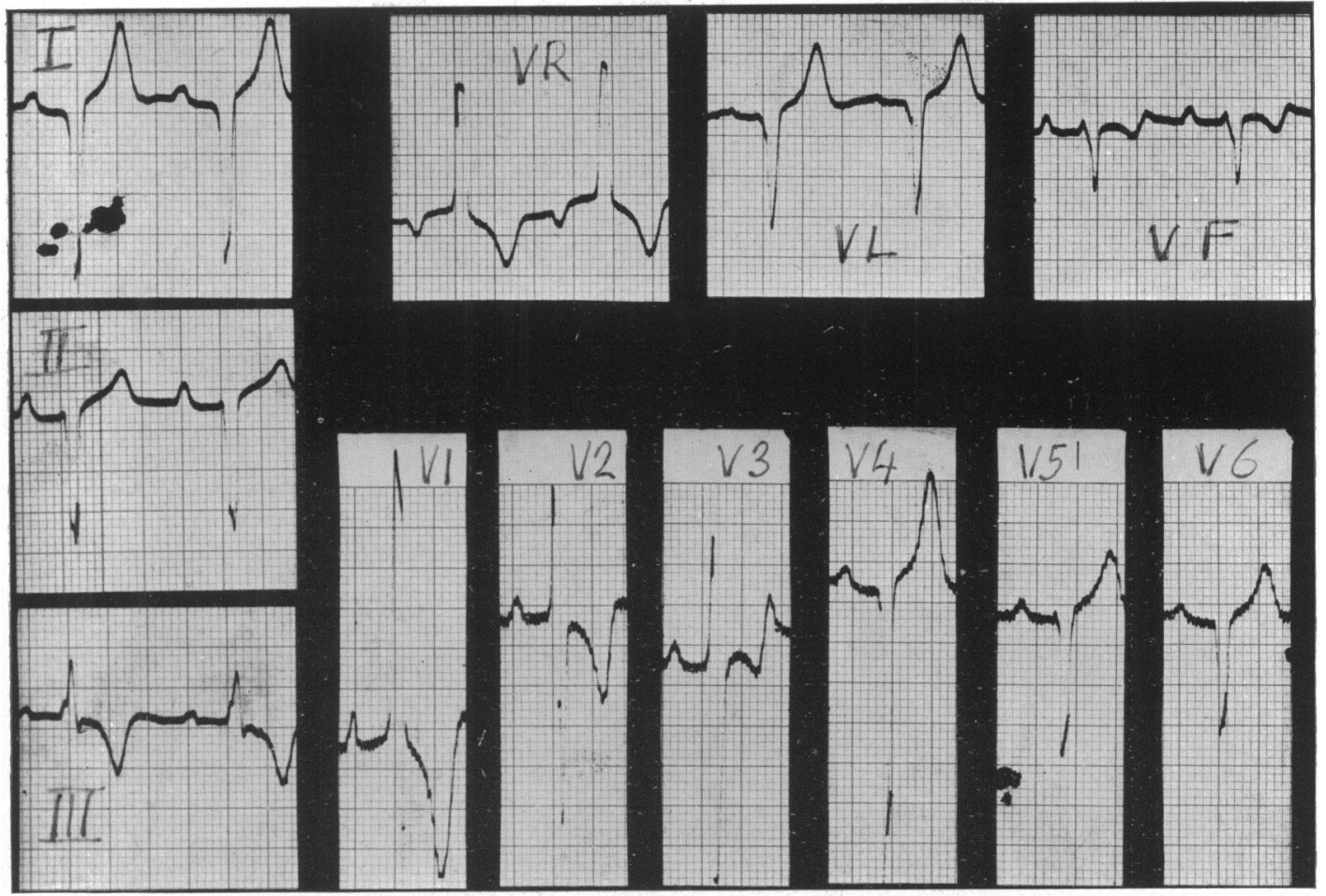

Fig. 7.-Standard and unipolar leads from Case P206 with pure pulmonary stenosis. Although relatively little disabled and just able to play cricket, there is right ventricular preponderance with deep $T$ inversion in leads III, VR, V1, and V2. The large R pattern with T inversion does not pass nearly as far to the left as in some other cases.

\section{The Diagnosis of Pulmonary Valvular Stenosis}

The diagnosis of pure pulmonary stenosis has often been overlooked in the past or it has been confused with Fallot's tetralogy, but this error is less likely to be made to-day by cardiologists experienced in congenital malformations of the heart, especially when facilities are available for cardiac catheterization and angiocardiography. The interatrial shunt with pure pulmonary stenosis can usually be differentiated from the right to left shunt in Fallot's tetralogy through the interventricular septal defect and over-riding aorta, both by the clinical picture and by angiocardiography.

Pulmonary valvular stenosis in Fallot's tetralogy. The recognition of valvular stenosis when it is a part of Fallot's tetralogy is more difficult. The systolic murmur and thrill in the pulmonary area are often more obvious than in the average case of Fallot's tetralogy and are likely to be maximal in the second rather than the third intercostal space. Much disability relative to the degree of cyanosis suggests that the pulmonary stenosis is of greater import than the over-riding aorta and we think this happens rather more often with valvular stenosis. At an early stage many of these patients were labelled as Fallot's tetralogy with special emphasis on the pulmonary stenosis, but this also applied to some cases of pure pulmonary stenosis. Squatting and the rightsided aortic arch are just as common as in other cases of Fallot's tetralogy.

Radiology and Angiocardiography. Some features of the angiocardiograms have been discussed by Campbell and Hills (1950), especially the slow emptying of the heart, and the aorta filling less quickly than in Fallot's tetralogy. The most important single sign of pulmonary valvular stenosis 
is the demonstration, both by plain radiography (Fig. 2, 3, and 9) and by angiocardiography (Fig. 8 and 18) of post-stenotic dilatation of the pulmonary trunk with delay in emptying of the contrast medium. This feature, common in pure pulmonary stenosis, is unfortunately not so common in Fallot's tetralogy, because the pulmonary trunk is often smaller and the over-riding aorta carries away more of the contrast medium. It may be easier to demonstrate an infundibular stenosis and thus exclude a valvular obstruction (except when the two co-exist, as they sometimes do) than to make a positive diagnosis. Valvular stenosis in Fallot's tetralogy is commoner than is often

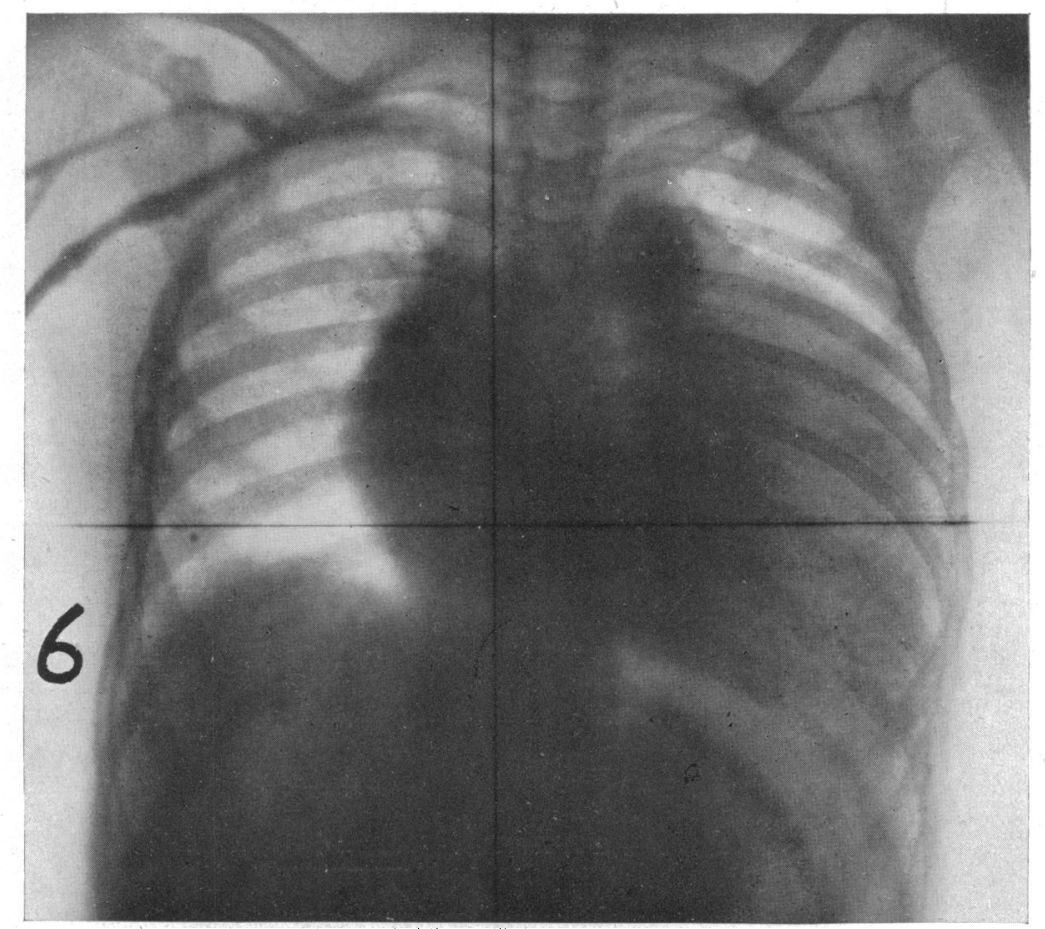

Fig. 8-Angiocardiogram at $6 \mathrm{sec}$. from Case 8 showing the $U$ shape of the right side of the heart: the dense shadow at the upper part of the limb indicates the dilated pulmonary trunk beyond the valvular stenosis. There is still very little filling of the lungs.

supposed and it is a fair working rule to suspect its presence whenever an infundibular stenosis cannot be shown by angiocardiography.

Diagnosis at operation. Often the final diagnosis can be made only at operation, and it is essential to open the pericardium to make a proper external examination of the heart (Brock, 1948). The differentiation between a valvular and a high infundibular obstruction may still be difficult, and sometimes may be possible only at cardiotomy or even at necropsy.

If the policy of direct operation on the pulmonary obstruction is to be implemented as often as possible, the obstruction must be exposed and its nature assessed, for this may disclose an unsuspected valvular stenosis in Fallot's tetralogy. If systemic-pulmonary anastomosis is performed, as a routine and without proper inspection of the heart, much valuable clinical information is overlooked, especially when a right-sided thoracotomy is used. 


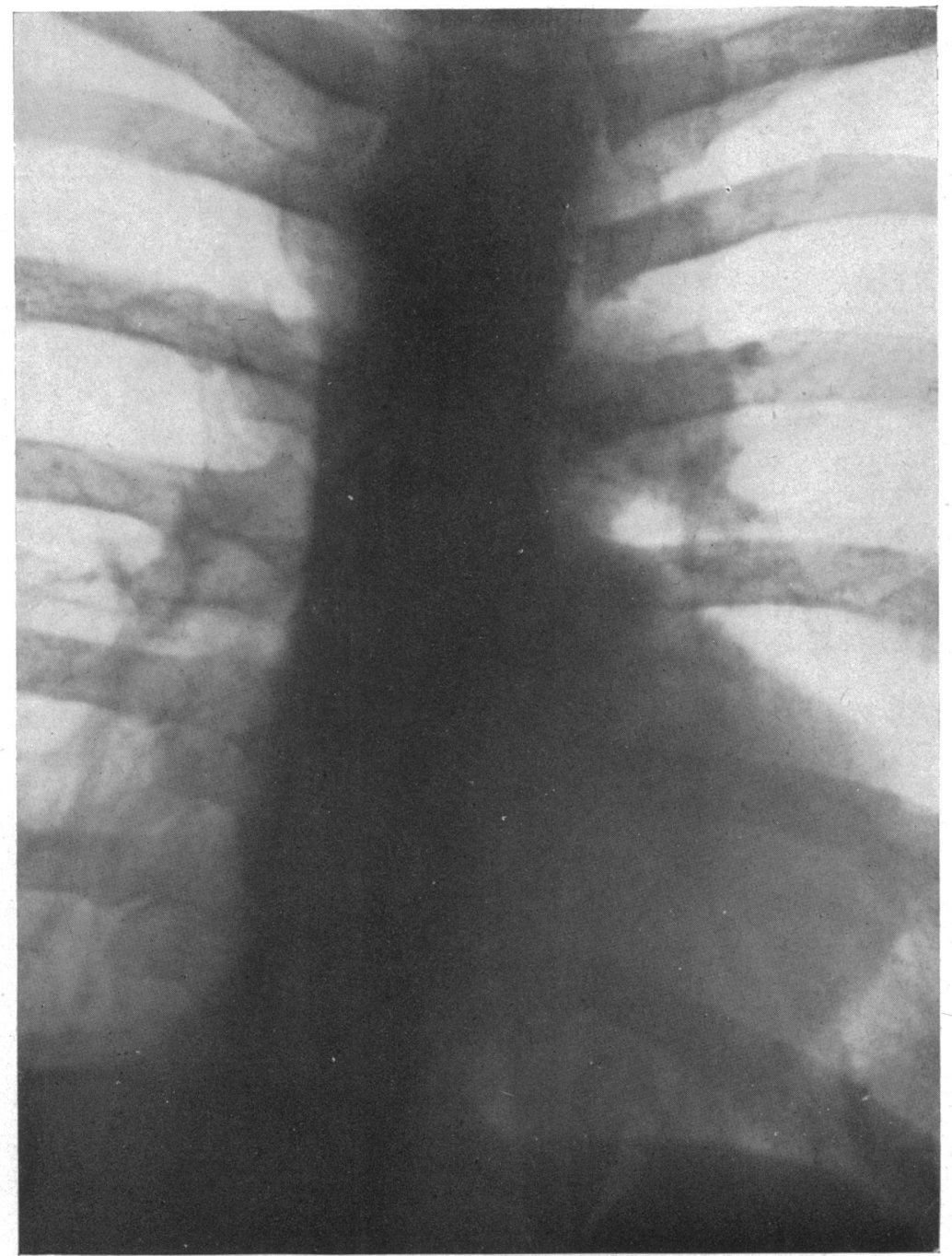

FIG. 9.-Teleradiogram from Case 4, showing a very raised apex of the heart from enlargement of the right ventricle, and dilatation of the pulmonary trunk and first part of the left pulmonary artery beyond the stenosis. The dilatation does not extend to the branches.

\section{Valvulotomy for Pulmonary Valvular Stenosis}

The advantages or otherwise of valvulotomy as opposed to a systemic-pulmonary anastomosis in Fallot's tetralogy with a valvular obstruction have been discussed (Brock, 1949). Whatever the merits or demerits of each method may be in Fallot's tetralogy, there can be no question of the advantages of valvulotomy for pure pulmonary stenosis. A systemic-pulmonary anastomosis not only fails to relieve the burden on the right ventricle but throws some extra work on the left ventricle. Although it relieves the cyanosis it introduced some risk, sooner or later, of heart failure. Congestive failure may appear within a few days of operation in unsuitable cases and can only be corrected if the valvular obstruction is divided and the systemic-pulmonary anastomosis undone (see p. 397). There can be no question that the right treatment for pure pulmonary stenosis is valvulotomy and a correct diagnosis is therefore important. 
The danger of operation. The serious prognosis of many cases with pulmonary stenosis has been described. We have learned to our cost that the risk of sudden death is the most grave danger to successful operation.

Cardiotomy and valvulotomy is, in contemplation, a somewhat alarming procedure but by the technique we have been able to evolve is not necessarily difficult; its hazards lie chiefly in this inherent liability to sudden cardiac failure or cardiac arrest. Moreover, our experience shows that this risk is very great in those older patients in the late teens or twenties who have become severely disabled and have a very large heart: the operative mortality is alarmingly high and it is important to select patients for operation before this stage has been reached. The risk is much less in younger patients with smaller hearts in whom cyanosis is slight or absent and the disability not so severe. Operation is then relatively safe and probably offers long years of increased activity.

The liability to sudden collapse or death is not confined to pure pulmonary stenosis but is also seen in Fallot's tetralogy with a valvular stenosis, and this has often been observed at operation. In seeking an explanation the most likely immediate cause is failure of the coronary circulation. The cardiac output is liable to be very small and if for any reason it is further reduced, the coronary circulation will suffer. Once this occurs a vicious circle is set up; the myocardial efficiency is impaired, output falls still further, and unless the collapse is checked death is inevitable. We know that the appearance of any deterioration in the patient's condition during operation for valvulotomy is an urgent indication to proceed at once to division of the valve; only in this way can the strain on the heart be relieved and the rapid downward spiral checked. This is supported by the two following cases.

Case 9, aged 22, had become worse at 18 years, since when he could walk no more than 50 yards. Pulmonary valvular stenosis with a patent foramen ovale was diagnosed, after catheterization.

The former diagnosis was confirmed as soon as the heart was exposed. Soon after the pericardium was opened the blood pressure, which had been $100 \mathrm{~mm}$., fell rapidly. All interference was stopped and the lungs were fully inflated, but the heart's action became so feeble that cardiac massage was begun and intravenous adrenalin given. Massage was maintained for some 15 minutes, when it became clear that the heart could not recover with this alone; the two ventricles seemed dissociated, the left contracting rapidly with moderate power, but the right ineffectively with only fibrillary twitching.

Valvulotomy to relieve the right ventricle seemed the only hope, though it was no easy decision to operate on a dying heart. Earlier experiences had, however, forced us to the conclusion that this would be necessary in such cases, although natural reluctance made us first attempt other means of resuscitation. The valve was divided: adrenalin was injected and massage resumed. The heart's action, which had virtually ceased, soon improved and the carotid pulse could be felt. Eventually, after further adrenalin a powerful and regular heart action was restored. At the end of the operation the blood pressure was $85 \mathrm{~mm}$. and the colour was good. The circulation was well maintained but consciousness was not fully recovered; the temperature rose to $107^{\circ} \mathrm{F}$. and other signs of cerebral anoxic damage appeared and death occurred 12 hours after operation.

This illustrates the need for immediate valvulotomy if the heart shows signs of distress; if the valve had been divided at once, complete recovery would probably have occurred. Although more than 20 minutes had elapsed before the valve was divided, it was possible to restore the heart's action, but unfortunately too late.

Case 23, a girl, aged 11, could at one time walk a mile but her limit steadily diminished until she could manage only 40 yards. A diagnosis of pulmonary valvular stenosis with a patent foramen ovale was confirmed by cardiac catheterization. At operation, although procaine solution had been given by intravenous drip and had been applied locally to the heart, it became unduly irritable and developed runs of three extrasystoles as soon as the pericardium was opened. In spite of more procaine and a pause, the heart began to show obvious distress and the blood pressure fell to 50: at the same time, Dr. Reynolds, who had been watching the continuous electrocardiographic tracing, called out that signs of coronary insufficiency had appeared (Fig. 10). It was decided that valvulotomy must be done at once and it was performed forthwith without difficulty. The heart's action at once began to improve and within a few minutes the blood pressure had risen to $75 \mathrm{~mm}$. and the tracing steadily returned to normal. The patient made a good recovery. The final result is excellent, the arterial oxygen saturation having risen from 68 to 88 per cent.

The events in this last case and the evidence of coronary insufficiency just when the heart was noted to be showing signs of grave distress support the view that the final determining factor is 
the failure of the coronary circulation. There can be little doubt that if immediate valvulotomy had not been performed, this patient would have died on the table.

The tendency for these cases to die suddenly emerges from our operative experience. We know now that it was almost impossible to avoid some of the earlier fatalities however careful a technique had been used. With our present technique and our awareness of the need for prompt action when there are signs of the heart failing, we might have avoided some of the other deaths.

A bare perusal of the figures suggests that pulmonary valvulotomy is a dangerous procedure with a high mortality: with proper selection of cases and improved technique in cardiotomy and

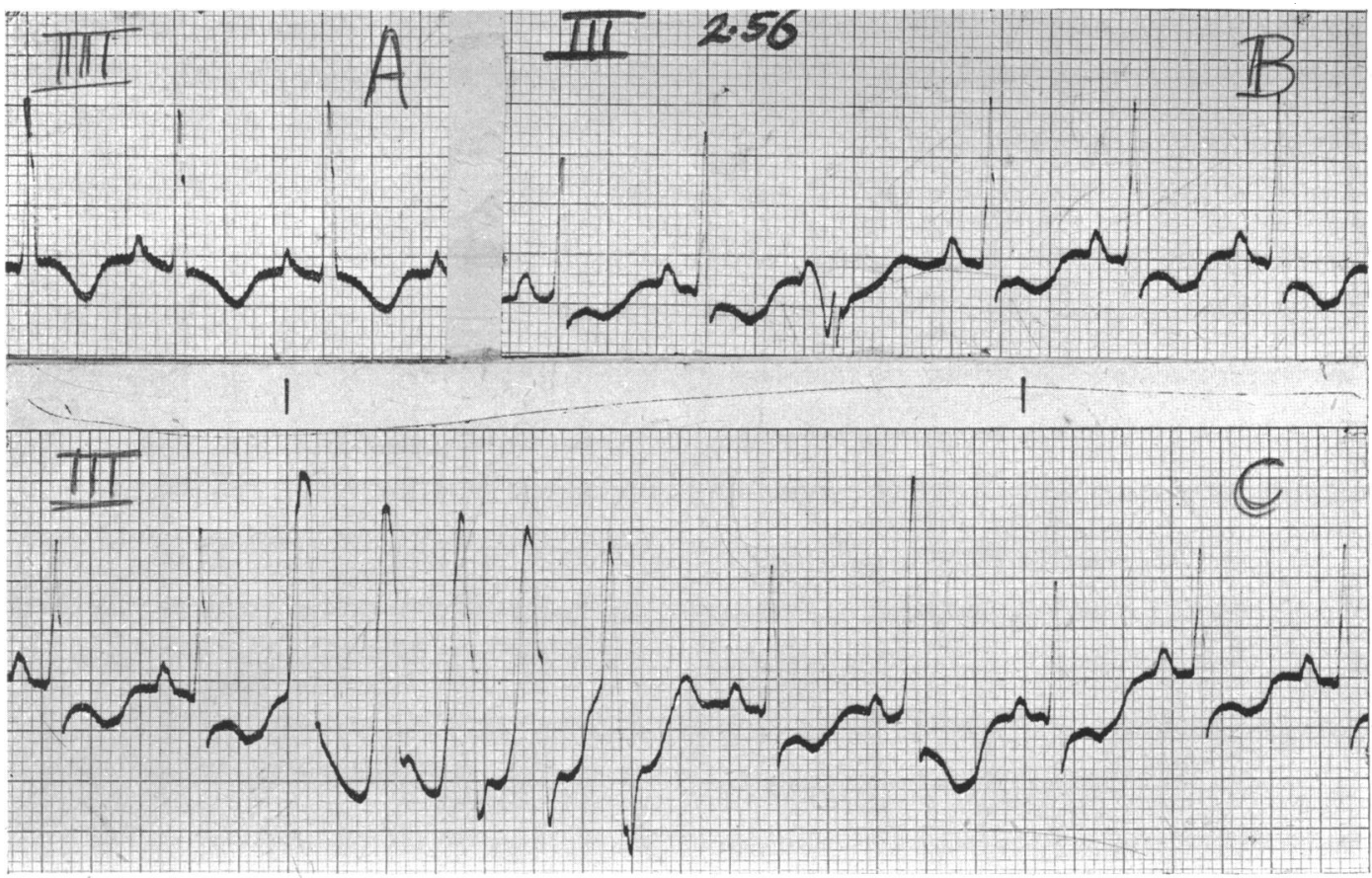

FIG. 10.-Electrocardiograms (lead III) from Case 23 during the operation of valvulotomy. In (A) 20 minutes earlier, these are three fairly normal beats, though $\mathrm{T}$ I was smaller and T III less inverted than at the start. In the continuous tracing $(B)$ and $(C)$, taken when controlling sutures were being put in the right ventricle, there is increased S-T depression and runs of ventricular extrasystoles-changes that became less ten minutes later when the punch had been used; they had almost disappeared when the operation was completed.

valvulotomy it should be much lower and the results good. This has been the experience in the development of most major operations, and so in the evolution of pulmonary valvulotomy we have to report a high overall mortality that will, we believe, become much lower now that so much valuable experience has been gained.

\section{The Technique of Cardiotomy for Pulmonary Valvulotomy}

Although this paper is not primarily concerned with the surgical aspects of pulmonary valvulotomy but rather with the results of the operation, the technique used must be described simply in so far as it has a bearing. The use of procaine solution, both intravenously and locally, to control tachycardia and arrhythmia and in general to reduce the irritability of the heart is essential to the safe conduct of these operations.

In our earlier cases we did not use intravenous procaine solution as a routine, but reserved it for injection as occasions arose, either intravenously or into the left atrium. Our present practice is to start an intravenous drip of 0.4 per cent procaine in glucose at the beginning of the operation 
and to continue if there is tachycardia or any form of cardiac irritability. In addition, we use 4 per cent procaine solution for application within the pericardium and to the surface of the heart, and 0.5 per cent solution for injection into the ventricular muscle. At first we used a 5 per cent solution for local application but have found that it produces local irritation as shown by intense hyperæmia; the 4 per cent solution does not do this.

A curved inframammary incision is now used with detachment of the pectoral muscles from their origin; the high transverse incision cutting across these muscles has been abandoned. The chest is opened through the third intercostal space with division of the third and fourth costal cartilages. As soon as the pericardium is exposed a small hole is made into it and $6 \mathrm{ml}$. of 4 per cent procaine solution are injected into the pericardial sac. If this is done at once the procaine solution will have been in the pericardium for some 5-10 minutes by the time the chest is fully open and all is prepared for cardiotomy. It is better not to open the pericardium until the solution has been in for at least five minutes.

The pericardium is opened by a long incision just in front of the phrenic nerve, and then by forward extensions from the top and bottom a large flap is made, hinged medially. If the heart shows any undue irritability it is as well to pause while more intravenous procaine is given. A swab moistened with 4 per cent procaine is also applied to the anterior surface of the right ventricle. Any undue traction upon or rotation of the heart must be avoided, as this is especially likely to cause signs of distress. During all these manipulations the systemic blood pressure should be frequently recorded and the surgeon informed at once of any change. Tachycardia is especially important, and if it persists a pause must be made to enable the heart to settle and more procaine solution to be given. The anæsthetist must ensure adequate aeration of the lungs and must not allow deflation.

About $10 \mathrm{ml}$. of 0.5 per cent procaine solution are now injected into the exposed surface of the right venticle at the site of proposed cardiotomy. It is desirable to make frequent short pauses after each of these steps to allow the heart to settle and to prevent any summation of effect by too rapid and continued stimulation, remembering always that if the heart begins to show signs of distress and the blood pressure falls, it is better to proceed at once to valvulotomy.

The technique of the actual cardiotomy has been greatly simplified through experience. We have abandoned the use of two rows of interlocking mattress sutures, which are neither necessary nor desirable; they may indeed be harmful, especially if they are pulled on too vigorously by an assistant. It is possible to dispense entirely with controlling sutures but we prefer in most cases to use two stay sutures placed one on each side of the proposed site of incision into the heart. These are left quite slack and are used solely to alter slightly the position of the heart if it is necessary to do so; they may be likened to reins guiding the heart. They are not used to control bleeding; this is all done by simple pressure with the pulp of the index finger.

An incision is made into but not completely through the wall of the ventricle; the final entry into the heart is made with a special curved probe, $4 \mathrm{~mm}$. in diameter, which is at once passed to confirm
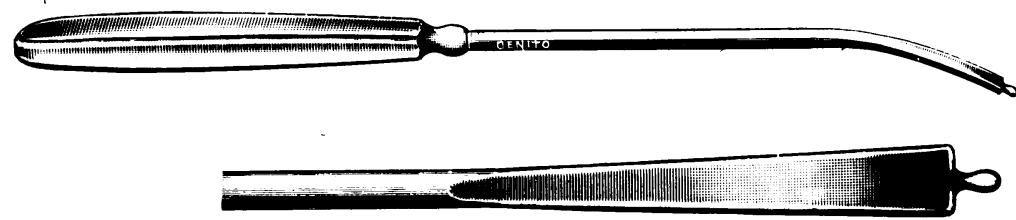

Fig. 11.-Curved and shouldered probe that is passed to confirm the level of the obstruction. This forms part of a graded set with those shown in Fig. 12 and 13.

the presence of the valvular obstruction and to make the first increase of passage into the pulmonary artery. A shouldered probe may be passed to confirm the obstruction at the valve level (Fig. 11). A special curved valvulotome is now inserted and the valve is divided instantaneously (Fig. 12C); as the instrument is withdrawn the index finger of the left hand controls bleeding, which should be 
slight. It is as well to pause for a short time before the incision in the valve is enlarged by a series of graded bougies (Fig. 12B) ; and finally by a special dilating instrument that splits the valve completely across transversely (Fig. 13). It must be emphasized that the diaphragm formed by the

A

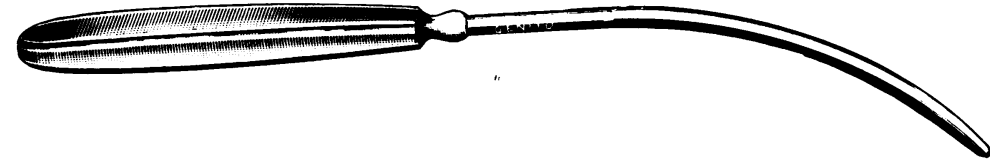

B

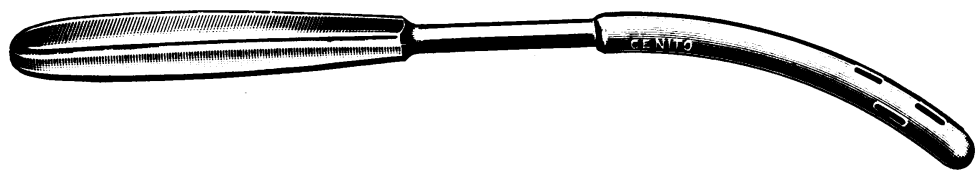

C

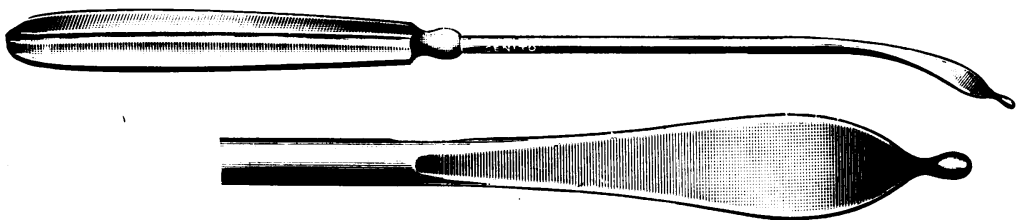

Fig. 12.-(A) A curved probe that is used to enter the heart, to identify the route into the pulmonary artery, and to make the first passage through the stenosed valve. (B) A curved bougie, one of a set of various sizes $(0.7 \mathrm{~cm}$., $1.0 \mathrm{~cm} ., 1.25 \mathrm{~cm}$.); it is hollow and fenestrated and has a terminal opening so that the circulation is not completely arrested when it is passed through the valvular stenosis. The bougie portion screws off from the handle so that it can be washed after use. (C) A valvulotome, one of a set of various sizes $(0.7 \mathrm{~cm} ., 1.0 \mathrm{~cm} ., 1.25 \mathrm{~cm}$.); the probe engages readily in the central aperture of the valvular stenosis and very slight pressure causes the two advanced cutting edges to sever the valve on each side; the receding edges are blunt and allow a smooth, safe withdrawal.

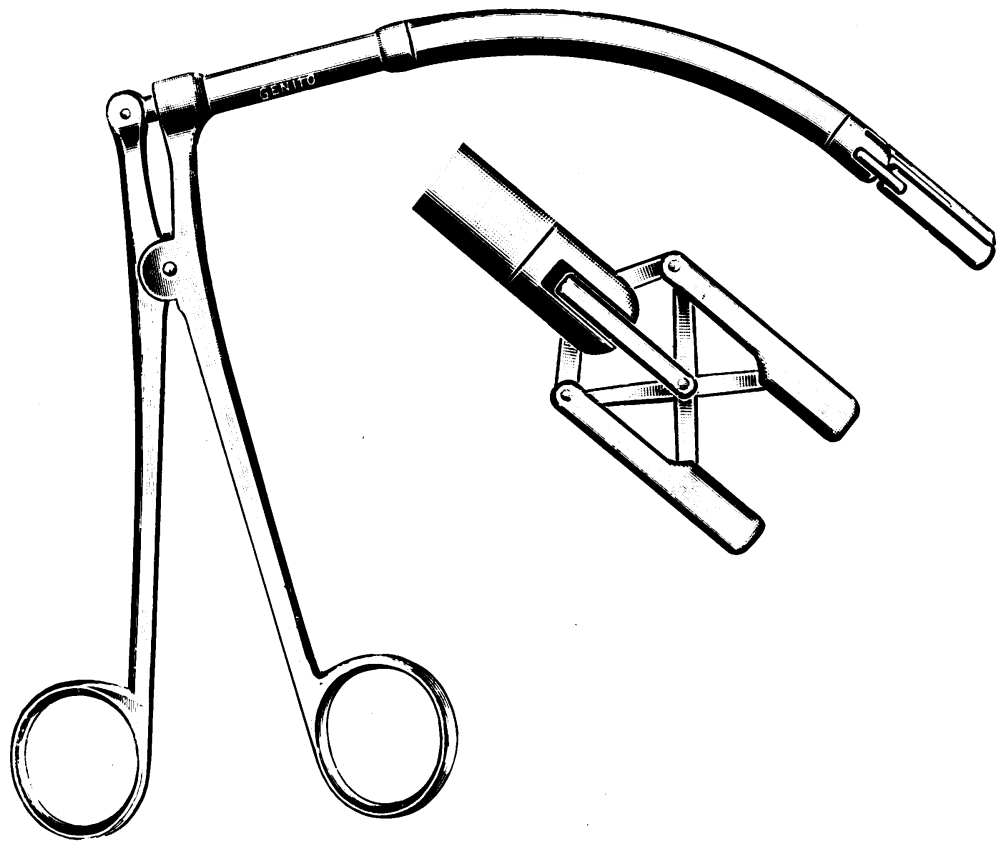

Fig. 13.-This is a dilating instrument, $0.7 \mathrm{~cm}$. in diameter, that is inserted after the valvulotome has been used. When it is opened the valve can be felt to split across; it opens to a diameter of $2.5 \mathrm{~cm}$. Its construction allows wide and powerful dilatation of the valvular stenosis without causing bleeding from opening or splitting of the incision in the heart wall, as happens if a hinged instrument is used. 
stenosed valve is merely cut across transversely so that two wide cusps are formed that allow the valve to remain competent. No part is excised as this might allow a serious regurgitation to occur.

The incision in the ventricle is closed by interrupted silk sutures; usually no more than three stitches are needed. The pericardial flap is sewn into place with interrupted sutures but the sac is not completely closed so that tamponade is avoided. The chest is always drained for 18-24 hours.

\section{The Deaths AFTer Operation}

Some details of the 10 deaths are given in Table III; 3 of these occurred before valvulotomy was done, usually soon after the chest was opened. They are really deaths from anæsthesia (Case 11) or from thoracotomy (Cases 1 and 8), and illustrate the inherent gravity of any operation in the presence of severe pulmonary valvular stenosis. For example, Case 11 had become much worse in the previous two years and a few days before operation went unconscious and was thought to be dying. Case 1 had gross congestive failure and Case 8 had a large pulsating liver: both had a very large heart (see Fig. 1). We know now that such patients are very liable to develop an arrhythmia and to die suddenly. Procaine solution was not used as freely as it would be now, and in Case 8, as soon as the pericardium was opened and the heart touched with a needle for intramuscular injection of procaine solution, ventricular fibrillation started and soon proved fatal. In a fourth (Case 9) death would have occurred in the same way had not valvulotomy been performed in an attempt to resuscitate the heart, an attempt that proved successful for several hours (see p. 386). These four patients would have died in similar circumstances whatever type of operation had been contemplated.

TABLE III

Analysis of 10 Fatal Cases

\begin{tabular}{|c|c|c|c|c|c|c|}
\hline Case & $\begin{array}{c}\text { Age } \\
\text { and sex }\end{array}$ & $\begin{array}{l}\text { Diag- } \\
\text { nosis* }\end{array}$ & $\begin{array}{c}\text { Case No. } \\
\text { in Allanby } \\
\text { \& Campbell } \\
(1949)\end{array}$ & Time of death & Cause of death & $\begin{array}{l}\text { Valvulo- } \\
\text { tomy done }\end{array}$ \\
\hline $\begin{array}{l}1 \\
5 \\
6 \\
8 \\
9 \\
\\
11 \\
12 \\
19 \\
21 \\
28\end{array}$ & $\begin{array}{l}\text { F22 } \\
\text { F29 } \\
\text { F23 } \\
\text { F9 } \\
\text { M20 } \\
\text { F11 } \\
\text { M14 } \\
\text { F20 } \\
\text { F7 } \\
\text { F24 }\end{array}$ & $\begin{array}{l}\text { PVS } \\
\text { PVS } \\
\text { FT } \\
\text { PVS } \\
\text { PVS } \\
\text { PVS } \\
\text { PVS } \\
\text { PVS } \\
\text { FT }+ \\
\text { FT }\end{array}$ & $\begin{array}{l}\text { Case } 3 \dagger \\
\text { Case } 4 \dagger \\
\text { Case } 1 \dagger \\
\text { Case } 6 \dagger\end{array}$ & $\begin{array}{l}\text { Soon after chest opened } \\
\text { Six hours later } \\
\text { Towards end of operation } \\
\text { Soon after chest opened } \\
\text { Twelve hours later } \\
\text { During induction of anæsthesia } \\
\text { Towards end of operation } \\
\text { Ten days later } \\
\text { One hour later } \\
\text { Eleven hours later }\end{array}$ & $\begin{array}{l}\text { Cardiac arrest } \\
\text { Hæmothorax } \\
\text { Cardiac arrest } \\
\text { Ventricular fibrillation } \\
\text { Cerebral anoxia } \\
\text { Cardiac arrest } \\
\text { Cardiac arrest } \\
\text { Myocardial infarction } \\
\text { Cardiac arrest } \\
\text { Cerebral anoxia. Low } \\
\text { blood pressure }\end{array}$ & $\begin{array}{l}\text { No } \\
\text { Yes } \\
\text { Yes } \\
\text { No } \\
\text { Yes after } \\
\text { collapse } \\
\text { No } \\
\text { Yes } \\
\text { Yes } \\
\text { Yes } \\
\text { Yes }\end{array}$ \\
\hline
\end{tabular}

* PVS = Pure pulmonary valvular stenosis : FT=Fallot's tetralogy with valvular stenosis.

$\dagger$ The clinical features and pathological anatomy of these cases have been fully reported, by Allanby and Campbell (1949).

$\ddagger$ Aorta arising mainly from right ventricle.

Short notes of the points of interest in the remaining 6 cases follow.

Case 5, a woman, aged 27, had lost much ground in the preceding year, with congestive heart failure and an attack of unconsciousness. She was in good condition after operation but died some 6 hours later and was found to have a large hæmothorax. This was before we had learned the need for draining the pleura in every case to guard against this risk. However carefully hæmostasis is observed, these severely cyanotic patients may bleed into the chest after any thoracic operation and die suddenly unless blood can drain away freely: the drainage of blood also reveals the need for its replacement.

Case 6, a woman, aged 24, with Fallot's tetralogy, had lost much ground in the year before operation. The valvular obstruction was severe with extensive calcification that occupied more than half of the valve 
and extended out to the arterial wall. The myocardium in such late cases has generally suffered and seems unable to stand the strain of cardiotomy and the secondary mechanical adjustments that are needed when the valve is divided.

Case 12, is discussed later (see p. 397).

Case 19, a girl, aged 20, who was deeply cyanosed was greatly improved at once after the pulmonary obstruction had been relieved, and was apparently doing well until suddenly on the tenth day she collapsed and died in an hour or two of pulmonary odema. Necropsy revealed two areas of myocardial infarction in the right and one in the left ventricle; both were some distance from the incision in the heart wall.

Case 21, a girl, aged 7, had Fallot's tetralogy; valvulotomy was followed by a period of about 10 minutes anxiety during which the cardiogram suggested coronary insufficiency. Her condition appeared all right when she left the theatre but she died suddenly about 15 minutes later. At necropsy the severe valvular stenosis was confirmed and also the interventricular septal defect: the aorta arose, however, almost entirely from the right ventricle, the over-riding being fully nine-tenths. Such cases are always dangerous operative risks.

Case 28, a girl, aged 23, with Fallot's tetralogy, had deteriorated greatly during the last year, the distance she could walk having shortened from a mile to 100 yards. At operation the valve was split and the pressure in the pulmonary artery raised satisfactorily with the development of a strong thrill. Her condition afterwards was only fair ; the blood pressure remained at about 70 ; and though no focal neurological signs developed she did not regain consciousness and died in about six hours. At necropsy the diagnosis of valvular stenosis was confirmed and the splitting of the valve seemed adequate had she recovered.

In 7 of the 10 fatal cases and in at least 3 of the successful cases, the immediate outlook was extremely bad and it is clear that the surgeon was being asked to perform a very difficult task in improving their condition. It was unfortunate that so many of the early cases were over 20 years of age, as the risk then is certainly greater.

\section{SUCCESSFUl Results OF Operation}

Twenty-three patients have survived operation and some details of these are given in Table IV. In 11 of these pure pulmonary valvular stenosis was present. In 12 the valvular stenosis was part of a Fallot's tetralogy: there was no doubt that the stenosis was valvular in all these cases except perhaps in Cases 2 and 4 where there may have been a high infundibular stenosis. In Cases 20 and 24 there was infundibular as well as valvular stenosis; the former was treated by resection in one case and by dilatation in the other.

\section{TABLE IV}

\section{Analysis of the 23 Successful Cases}

Pure Pulmonary Stenosis (11 cases)

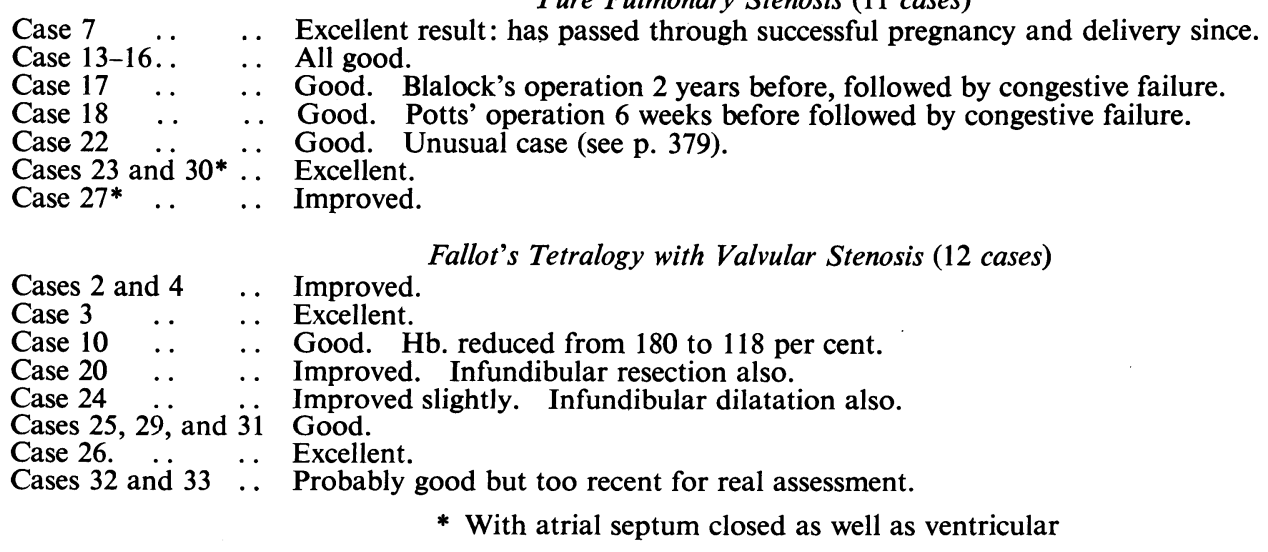

\section{Pure Pulmonary Valvular Stenosis}

The 7 deaths have already been mentioned: in 6 of these the immediate outlook was grave and earlier operation before the patient had become so severely disabled would have been much safer. 
On the other hand, the result in Case 7 shows that success is not impossible even at such a late stage: she was losing ground rapidly so that she could hardly walk the length of the ward and seemed unlikely to live many months; yet the result was extremely good (Fig. 14), so that she can get about freely with a colour that is almost normal.

Case 7 (0207) was 26 when she was first seen. Congenital heart disease was diagnosed when she was 18 months old. She led an active life, able to go skating and to take strenuous exercise until she was 18 : no comments seem to have been made about her colour or about cyanosis up to this stage.

When she was 18 she became increasingly cyanosed and could do less and less, till she could only walk 100 yards or less instead of several miles; she was almost completely incapacitated after a meal. Clubbing of the fingers was noticed when she was 24 and her deterioration from 24 to 26 was much greater than from 18 to 24 years. In fact, between July and October, while she was waiting admission she became so much worse that it was thought unlikely that she would live long. She had a moderate-sized hæmoptysis on two occasions and many dizzy attacks during these months. She never squatted.

On examination there was a fairly high-pitched systolic murmur in the second left space. A faint thrill could sometimes be felt but with no constancy. The heart showed slight enlargement, mainly due to the right ventricle; the pulmonary artery was a little prominent, though the lungs were oligæmic. The cyanosis and clubbing of the fingers were extreme, and both had increased in the five months since she had first been seen.

Circulation times, $12 \cdot 2$ seconds arm-tongue and $10 \cdot 0$ seconds arm-lung, and cardiac catheterization indicated a right to left shunt; the mean pressure in the right ventricle was $85 \mathrm{~mm}$. and in the pulmonary artery only $11 \mathrm{~mm}$. $\mathrm{Hg}$. At least one pulmonary vein seemed to drain into the right atrium as a fully oxygenated specimen was obtained from this site. The clinical diagnosis of valvular pulmonary stenosis with a patent foramen ovale was, therefore, supported.

At operation (December 6, 1948) the appearances even through the intact pericardium were characteristic of a valvular stenosis; the pulmonary artery was dilated and a fine jet-like thrill could be felt impinging on its wall. The absence of sinuses of Valsalva was confirmed and a diaphragmatic valvular obstruction could easily be felt.

Her progress after operation caused no anxiety. Her colour was almost normal at once and as soon as she got up she could walk better. Within a month she could climb two flights of stairs with little dyspnœa. Four months after she was getting about all day and had walked three miles with ease. Her colour was normal except for slight cyanosis in the nails, and the clubbing was disappearing. The hæmoglobin was now 87 per cent, and the arterial oxygen had risen from 69 to 85 per cent. She had already become pregnant in spite of advice to the contrary. Naturally this was viewed with great anxiety, but under regular observation there was no return of cyanosis or disability: her pregnancy was, therefore, allowed to continue. Her child, which was three weeks premature and weighed $5 \mathrm{lb} .5 \mathrm{oz}$., was born after a natural labour, only eleven months after operation. Her convalescence was uneventful.

Fourteen months after operation she was leading a normal life and doing everything except the heavy work; she had been pushing the child out in the pram and had never felt dyspnœic except once, pushing it over a steep bridge. The physical signs were unchanged except that the systolic murmur was rather louder. If there was any change in her heart size the cardio-thoracic ratio had diminished, 48 against 50, these figures being the average of several observations (Table VII). The lung fields looked rather more dense (Fig. 15). There was still right ventricular preponderance, but perhaps some diminution of right ventricular strain (Fig. 16C). Eighteen months after operation this improvement is maintained and if anything the heart is a trifle smaller.

It seems certain that the pressure on the right side has fallen sufficiently to stop the right to left shunt that was present previously. Without the excellent results of Cases 3 and 7 we might have felt discouraged from proceeding on these lines.

One important feature that has emerged from our experience with valvulotomy is that operation 


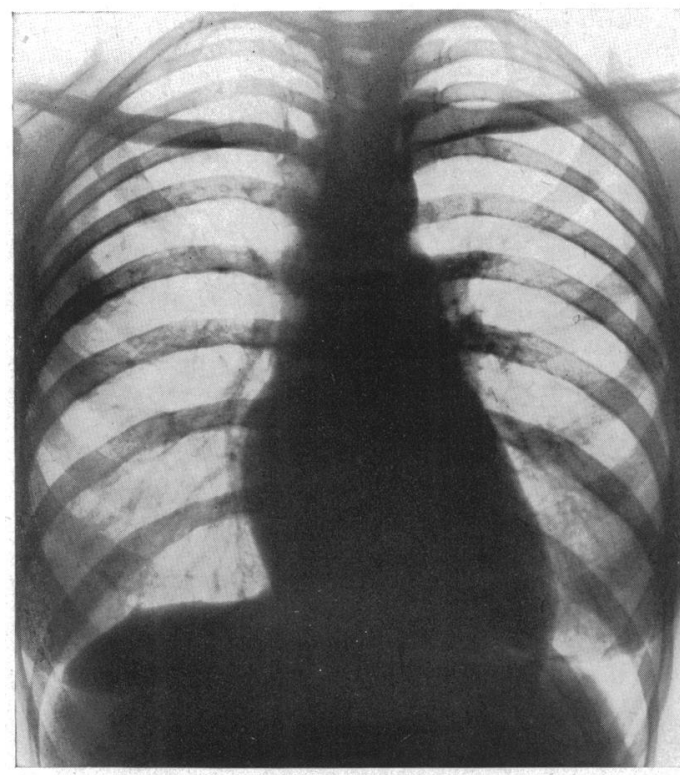

A

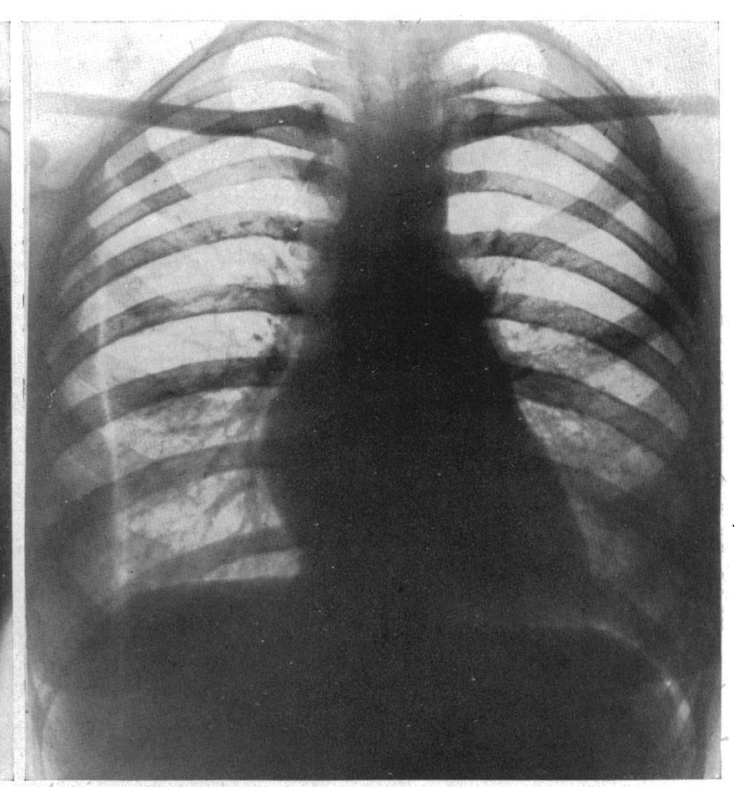

B

Fig. 15.-Teleradiograms (A) before and (B) four months after operation, showing no change in the heart size but much improvement in the vascularity of the lung fields. This is well shown in the right pulmonary artery and its branches, which now have a more normal shape and can be followed more clearly. From Case 7, who showed great improvement.

I

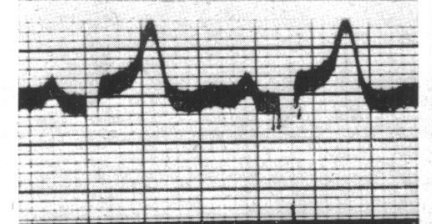

II

III

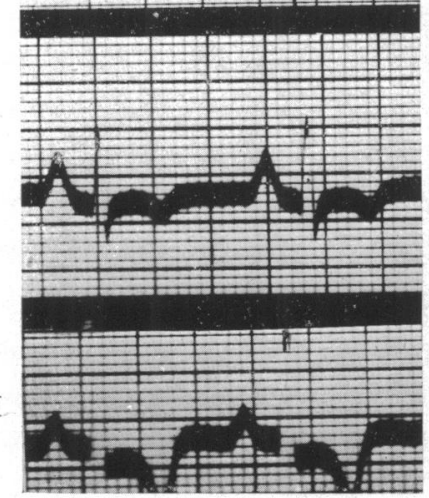

A

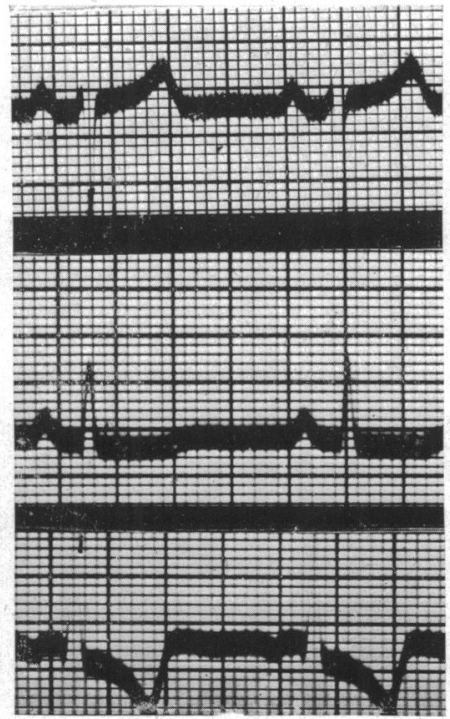

B

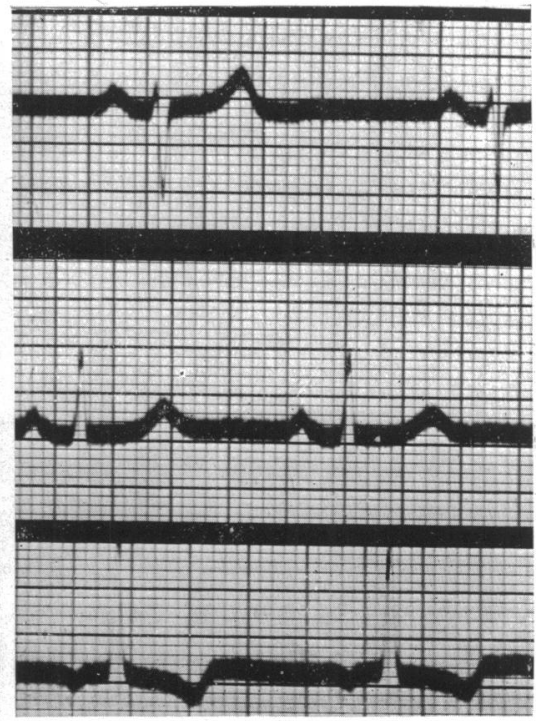

C

FIG. 16.-Electrocardiogram after successful valvulotomy for pure pulmonary stenosis. (A) Before operation. (B) One month, and (C) one year after, showing an upright instead of an inverted $T$ II and much less inversion of $T$ III, suggesting some disappearance of left ventricular strain. In the chest leads there was still $T$ inversion in V1, V2, and V3 so that the limb lead changes may be partly postural. Case 7.

should be advised earlier before the heart muscle has become so damaged with gross hypertrophy and fibrotic changes. One side of the picture, the gravity and danger of the operation, has already been shown. The other, much more satisfactory side, is shown in the later patients where the 
changes had not advanced so far: the operative mortality in these has been low and the results, up to date, excellent.

This group consists of 10 patients $(13-18,22,23,27$, and 30$)$ all under 14 ; most were less severely cyanosed, although in several a large heart caused extra anxiety. Six of these were operated upon at the Johns Hopkins Hospital, by the courtesy of Dr. Helen Taussig and Dr. Alfred Blalock, and Fig. 17 shows the group, all of whom had undergone pulmonary valvulotomy within the three weeks before the photograph was taken. These patients were presented for operation with a view to assessing and, if possible, demonstrating its feasibility. The clinical results and the group picture

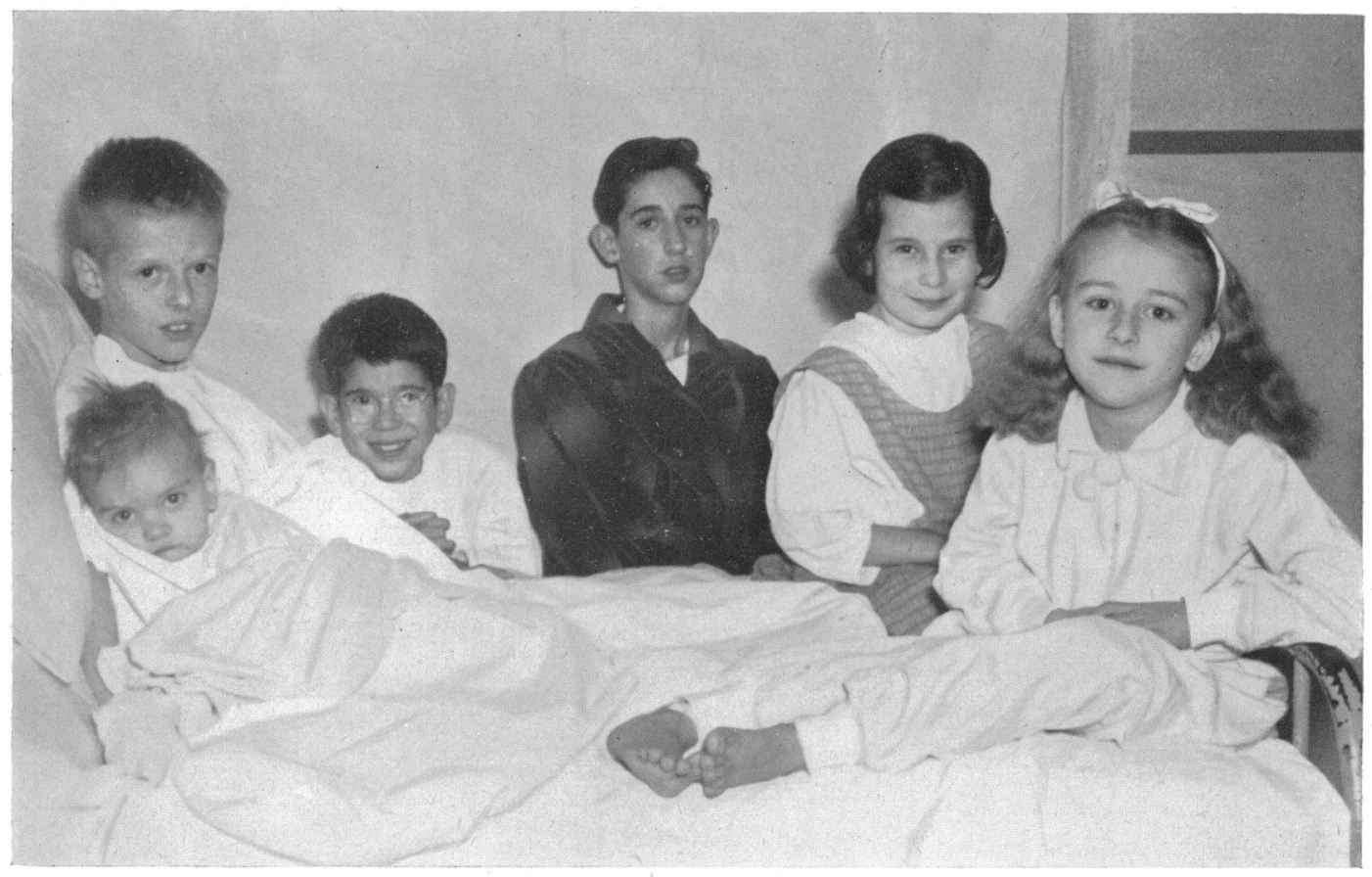

FIG. 17.-Group of six children who had undergone pulmonary valvulotomy at the Johns Hopkins Hospital, Baltimore, in the three weeks before the photograph was taken. (Cases 13-18).

both testify to its success. It was a great pleasure and privilege to be allowed to perform these operations at the Johns Hopkins Hospital, and we understand that Dr. Blalock has continued this series.

These successful results demonstrate that pulmonary valvulotomy is reasonably safe provided it is done sufficiently early. The high mortality in our earlier patients, all of whom were advanced and severe, is not a true picture of the merits of the operation. We hope that no one else will be faced with such a series of dangerous cases as these constituted, though the excellent result in Case 7 shows that the desperate risk is sometimes justified and well rewarded.

\section{Valvulotomy for Well Compensated Cases with High Right Ventricular Pressure}

The demonstration that pulmonary valvulotomy can give good results with relative safety, providing it is done before the patient has deteriorated too much, inevitably introduced the question of its application to well compensated pulmonary stenosis. The position is well demonstrated by the following patient.

Case 30, aged 12, was found to have a murmur at two years of age. He had few symptoms 
and could run 100 yards and walk at least three miles. He was able to do most things with the boys at school, but became more tired and could not keep up with them for long and was not allowed to play games.

At one time he was thought to have a patent ductus arteriosus, and in August, 1949, he was seen at the Johns Hopkins Hospital by Dr. Taussig, who made a diagnosis of pulmonary valvular stenosis. Cardiac catheterization by Dr. Richard Bing revealed a pressure reaching 193/0 mm. Hg. in the right ventricle and $30 / 18$ in the pulmonary artery. Dr. Taussig recommended him to see R.C.B. for pulmonary valvulotomy.

When seen by us, in February, 1950, there was no cyanosis or clubbing of the fingers. There was a loud harsh systolic murmur, maximal in the pulmonary area, and a systolic thrill; the pulmonary second sound was normal. The heart was not enlarged (Fig. 2); the left pulmonary artery was easily seen on screening and the lung fields looked a little light. There was right ventricular preponderance with $T$ inversion in leads II and III and form V1 to V5 (Fig. 5). Angiocardiography (Fig. 18)

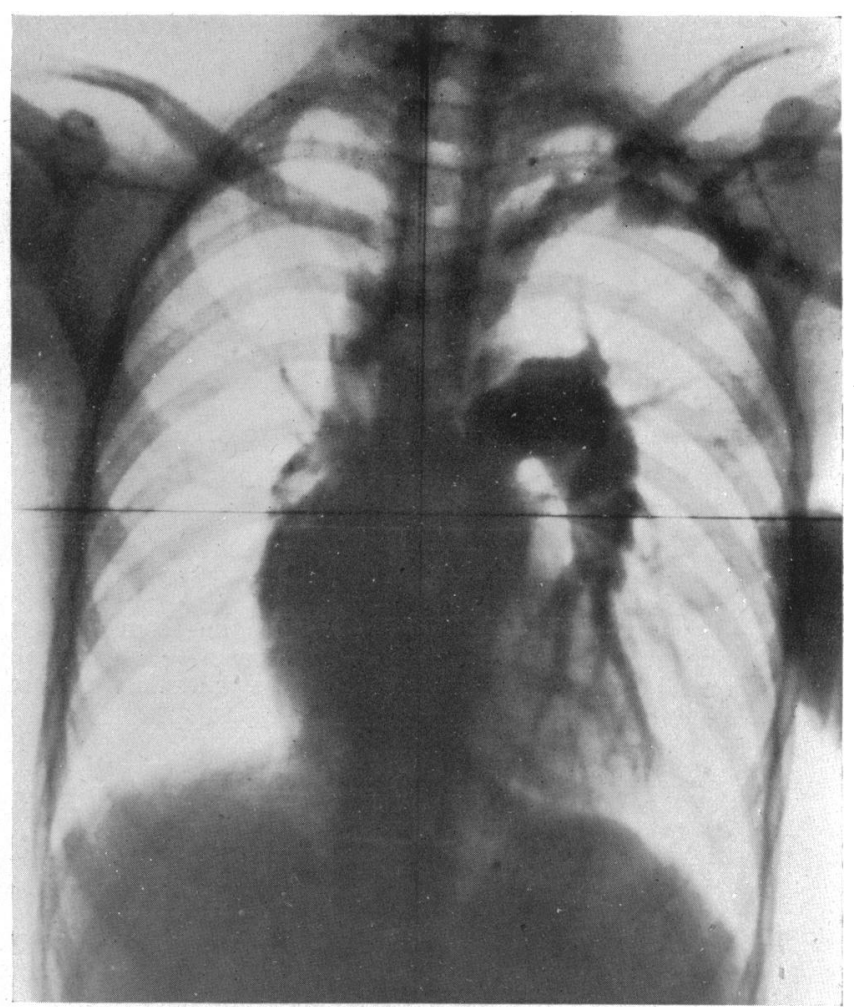

Fig. 18.-Angiocardiogram at $3 \mathrm{sec}$. from Case 30, with pure pulmonary stenosis. The $U$ shape of the right side of the heart is well seen and there is unusual dilatation of the left pulmonary artery, but little increase in the density of the lungs. More often the increased density is confined to the pulmonary trunk and shows a small circular shadow.

demonstrated a large pulmonary artery with a dilated left branch; there was no evidence of a shunt.

Because of the small heart and slight disability, it was felt wiser to repeat these investigations before deciding on an operation. Cardiac catheterization by Dr. Deuchar, gave almost identical results (see Tables V and VI and Fig. 19). An extremely high pressure 180/0 in the right ventricle and $22 / 10 \mathrm{~mm}$. $\mathrm{Hg}$. in the pulmonary artery confirmed pulmonary stenosis.

With such a high pressure in the right ventricle it seemed probable that he would not keep fit for long, and that sudden deterioration might make an operation much more dangerous and less likely to be effective. The increasing safety of valvulotomy is an indication for radical and prophylactic treatment to relieve this dangerous mechanical position before signs of failure appear.

At operation, the diagnosis was confirmed; valvulotomy was performed without event and was followed by a smooth recovery. It is as yet too early to assess the final effect but catheterization shows that the pressure in the right ventricle has been reduced to one half.

The implications of this are, however, so important that it demands presentation at this time for it serves, as it were, as the culmination of this work on pulmonary valvulotomy. It will be necessary to decide what level of right ventricular pressure is fraught with danger, for some patients get on well for long periods. 


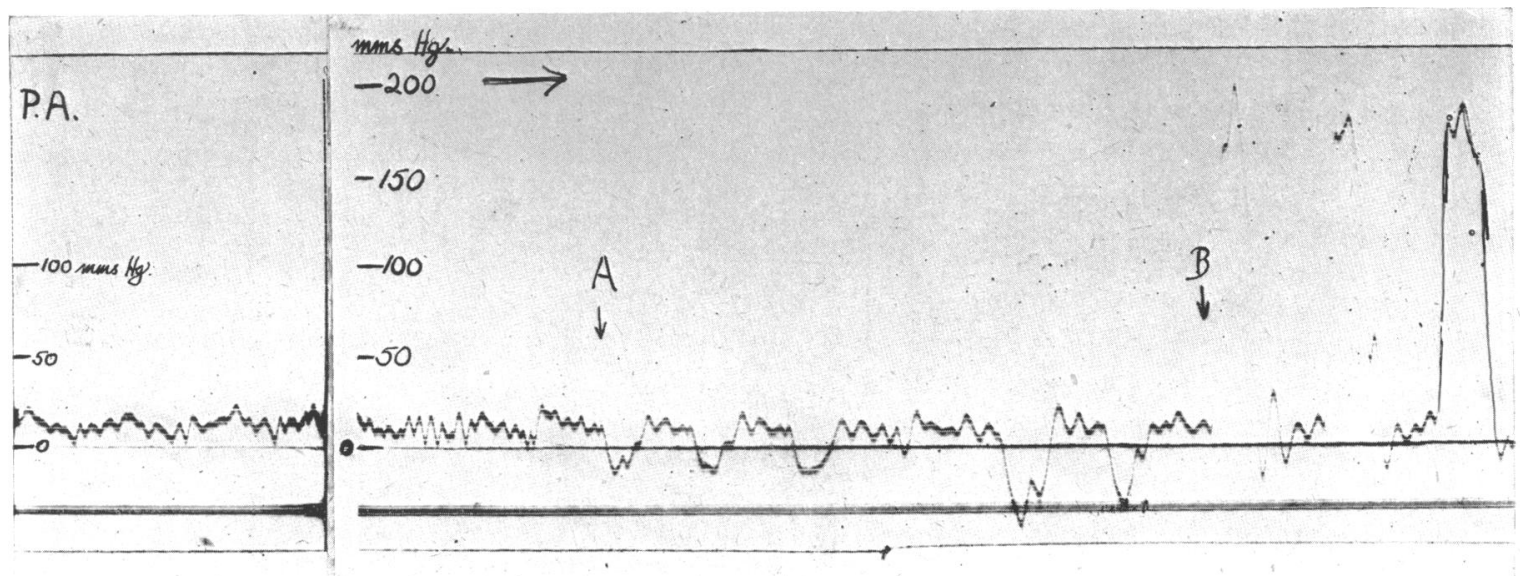

FIG. 19.-Pressure tracings from Case 30. Reading from left, to right the steady tracing shows the catheter in the pulmonary artery; then at A the catheter was withdrawn into the region of the pulmonary valve and at $B$, about 4 seconds later, into the cavity of the right ventricle. The tracing of the third heart beat after this, has been blacked in for clarity.

\section{Results of Catheterization in Pulmonary Valvular Stenosis}

Tables V and VI show some of the results of catheterization in pure pulmonary valvular stenosis. Each of the upper four cases had a right to left shunt, probably through a patent foramen ovale, and the arterial oxygen saturation lay between 52 and 79 per cent. Each of the lower four had a normal arterial oxygen saturation without evidence of any right to left shunt.

The pressure in the right ventricle seemed at least as high in these latter four cases without a

TABLE V

Some Results of Catheterization in Eight Cases of Pure Pulmonary Valvular Stenosis

\begin{tabular}{|c|c|c|c|c|c|}
\hline \multirow{2}{*}{ Case No. } & \multicolumn{3}{|c|}{ Pressure, mm. Hg. } & \multicolumn{2}{|c|}{ Pulmonary flow } \\
\hline & R.A. & R.V.* & P.A.* & litre/min. & $1 / \mathrm{min} . / \mathrm{sq}$. in. \\
\hline \multirow{6}{*}{$\begin{array}{r}7 \\
10 \\
11 \\
23\end{array}$} & \multirow{5}{*}{$\begin{array}{r}11 \\
9 \\
15 / 4 \\
3\end{array}$} & \multicolumn{2}{|c|}{ With a Patent Foramen Ovale } & \\
\hline & & \multirow{4}{*}{$\begin{array}{r}85 \\
45 \\
155 / 27 \\
44\end{array}$} & \multirow{4}{*}{$\begin{array}{l}11 \\
16 \\
-\end{array}$} & & \\
\hline & & & & \multicolumn{2}{|c|}{ one-third normal } \\
\hline & & & & - & - \\
\hline & & & & - & \\
\hline & & \multicolumn{2}{|c|}{ With Both Septa Closed } & & \\
\hline $\begin{array}{r}30 \\
0091 \\
\text { P206 } \\
0328\end{array}$ & $\begin{array}{c}12 / 5 \\
8 / 0 \\
10 / 0\end{array}$ & $\begin{array}{l}180 / 0 \\
155 /-8 \\
140 / 21\end{array}$ & $\begin{array}{r}22 / 10 \\
24 / 7 \\
40 / 21\end{array}$ & $\begin{array}{l}4.0 \\
5.9 \\
3.7\end{array}$ & $\begin{array}{l}3 \cdot 6 \\
4 \cdot 6 \\
2 \cdot 4\end{array}$ \\
\hline 0328 & $14 /-1$ & $135 / 8$ & $31 / 10$ & 1.9 & 1.9 \\
\hline
\end{tabular}

* The single figures represent mean pressures and the double figures systolic and diastolic pressures.

shunt, so that probably the foramen ovale was sealed in all of them. Case 30 has just been described; it is striking that the other three also have such high systolic pressures in the right ventricle, although their symptoms are relatively slight, e.g. Case 0091 is seeing whether he can manage to work as a carpenter and Case P206 is able to play some cricket at school. Nevertheless, we feel that these patients should probably be submitted to valvulotomy for the same reasons that Case 30 was, before deterioration starts. 
It is interesting that the pulmonary flow is so little, if at all, diminished in these patients, which shows that the extremely high pressure in the right ventricle has been effective in overcoming the obstruction of the stenosis. In contrast to these, some of the earlier cases operated on showed the lowest figures for the pulmonary flow of any that we have come across, and in Case 10 it was considerably reduced.

TABLE VI

The' Oxygen Saturation on Catheterization in Eight of these Cases

\begin{tabular}{|c|c|c|c|c|c|c|}
\hline \multirow{2}{*}{ Case No. } & \multicolumn{6}{|c|}{ Percentage $\mathrm{O}_{2}$ saturation } \\
\hline & S.V.C. & I.V.C. & R.A. & R.V. & P.A. & Systemic artery \\
\hline \multirow{6}{*}{$\begin{array}{r}7 \\
10\end{array}$} & \multicolumn{6}{|c|}{ With a Patent Foramen Ovale } \\
\hline & \multirow{2}{*}{$\overline{61}$} & - & 45 & 47 & \multirow{2}{*}{$(22)$} & 69 \\
\hline & & 75 & 67 & 67 & & \multirow{2}{*}{$\begin{array}{l}79 \\
52 \\
68\end{array}$} \\
\hline & 35 & 39 & $\begin{array}{l}32 \\
46\end{array}$ & 33 & $\overline{42}$ & \\
\hline & \multirow{2}{*}{\multicolumn{4}{|c|}{ With Both Septa Closed }} & & \\
\hline & & & & & \multirow{4}{*}{$\begin{array}{l}66 \\
75 \\
66 \\
41\end{array}$} & \multirow{4}{*}{$\begin{array}{l}97 \\
96 \\
95 \\
94 \cdot 5\end{array}$} \\
\hline 30 & 64 & 62 & 64 & 62 & & \\
\hline $\begin{array}{l}0091 \\
\text { P206 }\end{array}$ & $\begin{array}{l}74 \\
64\end{array}$ & 71 & $\begin{array}{l}75 \\
68\end{array}$ & $\begin{array}{l}74 \\
64\end{array}$ & & \\
\hline 0328 & 54 & 52 & 52 & 49 & & \\
\hline
\end{tabular}

\section{Valvulotomy afTer a SYSTEmic-Pulmonary ANAStomosis}

We have already indicated that the correct treatment of pure pulmonary valvular stenosis is valvulotomy: a systemic-pulmonary anastomosis should not be done, for sooner or later heart failure may ensue: a view that is shared by Taussig (personal communication). This was borne out by three of these cases, in each of which congestive heart failure followed promptly upon the systemic-pulmonary anastomosis. These three were all operated upon by one of us at the Johns Hopkins Hospital in November, 1949, and we would like to place on record our appreciation of the broadminded and scientific attitude that Dr. Taussig and Dr. Blalock showed in asking us to operate on these patients.

Case 12, a boy, aged 14, had a left-sided subclavian-pulmonary anastomosis done by Dr. Blalock $2 \frac{1}{2}$ years earlier; his cyanosis had been relieved but he soon developed congestive heart failure with a large pulsating liver. Though his condition was desperate, valvulotomy was performed without event and the subclavian pulmonary anastomosis was exposed with a view to closing it.

The lung was very adherent and while the many vascular adhesions were being divided the heart stopped suddenly about 30 minutes after valvulotomy had been done; it could not be revived. This patient with heart failure was not likely to live long unless some relief could be given. His was the only death among the seven pulmonary valvulotomies done by us at Baltimore.

Case 17, a boy, aged 9, had right-sided subclavian-pulmonary anastomosis by Dr. Blalock two years before. His colour had improved but he soon developed progressive heart failure with a large pulsating liver. After successful valvulotomy he showed some improvement with diminution in size and pulsation of the liver. His condition was not, however, satisfactory until three weeks later when Dr. Blalock himself closed the original subclavian-pulmonary anastomosis; he then made rapid and excellent progress. This shows that the artificial ductus provides the extra strain that the heart is unable to tolerate when there is no ventricular septal defect and over-riding aorta.

Case 18 is so far as we know, the first example of pulmonary valvulotomy and closure of an aorticpulmonary anastomosis at the same operation. The patient, aged 14 months, had shown progressive cyanosis since birth and became very much worse and nearly died after a respiratory infection. A left-sided Potts' operation was done elsewhere in October, 1949, and the colour improved immediately; three days later the liver showed progressive enlargement so that within a week it was very large and pulsating; the size of the heart also increased. Dr. Ziegler, after cardiac catheterization, made a diagnosis of pulmonary valvular stenosis with patent foramen ovale and congestive failure, and referred the baby to the Johns Hopkins Hospital for pulmonary valvulotomy. 2D 
This was performed successfully and was well tolerated, six weeks after the original operation. An attempt to close the aortic-pulmonary anastomosis was decided on: the two vessels and the stoma were dissected free and the fistula between the two was closed by a running mattress suture, and by three interrupted mattress sutures. The child (who is shown in the group photograph in Fig. 17) made a good recovery and has continued well since. Within six months he had doubled his pre-operative weight.

\section{Valvulotomy for Pulmonary Valvular Stenosis in Fallot's Tetralogy}

The 3 patients who died have already been described. The results in the 12 survivors are most encouraging, though in Cases 2, 4, 20, and 24 the improvement is less than usual.

The first three were operated on more than two years ago and the fourth in May, 1949. These four and Case 7 (see p. 392) have, therefore, been followed for long enough to show the degree of improvement to be expected. No patient has yet failed to maintain or improve the early improvement, so we hope the assessment of the more recent patients will prove to be correct.

These four cases will be given more fully so that the reader can judge their incapacity and their progress. Some facts given in Table II are omitted to save space: their electrocardiograms showed right ventricular preponderance, generally with a large pointed P II. Hearts that were little, if at all, enlarged have sometimes become a little larger after operation, and the measurements before and after are given in Table VII.

TABLE VII

Heart Size Before and After Pulmonary Valvulotomy

\begin{tabular}{|c|c|c|c|c|c|c|}
\hline \multirow[t]{2}{*}{ Case No. } & \multicolumn{2}{|c|}{ Cardio-thoracic ratio } & \multicolumn{2}{|c|}{$\begin{array}{l}\text { Max. transverse diameter } \\
\text { of Heart }(\mathrm{cm} .)\end{array}$} & \multicolumn{2}{|c|}{$\begin{array}{l}\text { Diameter of Chest } \\
(\mathrm{cm} .)\end{array}$} \\
\hline & Before & After* & Before & After & Before & After \\
\hline $\begin{array}{r}2 \text { (P079) } \\
3 \text { (H107) } \\
4(\mathrm{H} 109) \\
7(0207) \\
10(0153)\end{array}$ & $\begin{array}{l}49 \cdot 5 \\
49 \\
43 \\
50 \cdot 4 \\
52\end{array}$ & $\begin{array}{ll}54 \cdot 5 & (24) \\
52 \cdot 5 & (28) \\
46 & (21) \\
47 & (18) \\
52 & (12)\end{array}$ & $\begin{array}{l}12.0 \\
11.0 \\
11.6 \\
12.8 \\
13.0\end{array}$ & $\begin{array}{l}13 \cdot 25 \\
12 \cdot 25 \\
12.25 \\
12 \cdot 25 \\
13 \cdot 0\end{array}$ & $\begin{array}{l}24 \cdot 25 \\
22 \cdot 4 \\
26 \cdot 9 \\
25 \cdot 4 \\
25 \cdot 0\end{array}$ & $\begin{array}{l}24 \cdot 25 \\
23 \cdot 25 \\
26 \cdot 5 \\
26 \cdot 0 \\
25 \cdot 0\end{array}$ \\
\hline Average & $48 \cdot 8$ & 50.4 & $12 \cdot 1$ & $12 \cdot 6$ & 24.8 & 25.0 \\
\hline
\end{tabular}

* The figure in brackets denotes the number of months.

Case 2 (P079), aged 18. Pulmonary stenosis was diagnosed by one of us when she was two years old. She could walk no more than 200 yards in summer and hardly went outside in winter. She squatted constantly. Her cyanosis was slight at rest but increased greatly with any exertion. The physical signs were as usual in Fallot's tetralogy.

The immediate result of operation was difficult to assess because arterial emboli in the legs caused much pain on walking and at one time gave rise to some anxiety.

Eight months after operation she could walk a quarter of a mile with less discomfort. Two years after operation she had improved further and her legs had recovered completely. She had walked a mile, but could not always do this: the cyanosis was less. The physical signs and the blood pressure were not significantly changed. The only unusual feature was that the hæmoglobin had not diminished; it fell from 129 to 119 .per cent shortly after operation but had risen again to 130 per cent.

Case 3 (H107), aged 11, had never been able to walk more than 100 yards without distress, though she had sometimes struggled on for a quarter of a mile. She squatted frequently. On examination, the cyanosis was severe, with extreme clubbing of the fingers and polycythæmia (hæmoglobin 156 per cent). There was a loud systolic murmur in the pulmonary area and a slight thrill. The heart was sabot-shaped but not enlarged, and the lung fields were light. A diagnosis of Fallot's tetralogy was made.

A few days after operation (19/2/48) her colour was much better and progress was rapid, so that she was soon able to move about the hospital, with a colour quite unlike anything seen before. Unfortunately, the arterial oxygen saturation was not done before operation, but it was 81 per cent at this time and had risen to 91 per cent when it was done again a year later. 
Four months after operation she was leading a normal life at school except for games, and her colour at rest was normal. She was able to run about energetically. The parents often think that progress has continued for some months after operation; generally, this seems no more than improvement in the muscles and general condition as the patient leads a more normal life, but in this girl, real progress seemed to continue for some months longer.

Two years after operation her colour, even after exercise, is almost normal, and she is doing an increasing amount of drill, etc., at school; in fact, her capacity seems almost unlimited and she is able to do all she wants, though it has been thought wise not to allow more games at school.

There is a little increase in the size of her heart, c.t.r. 52.5 against 49 (Fig. 20), the average of three measurements before operation; the hæmoglobin has not increased again and has remained

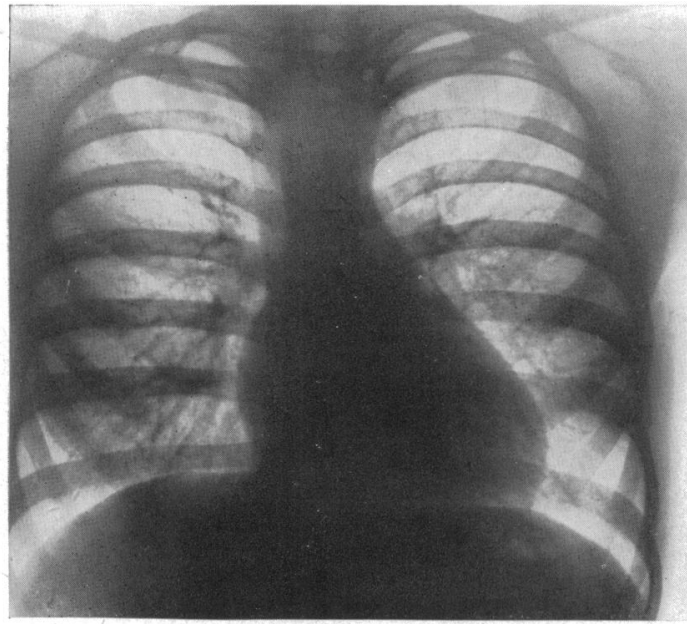

A

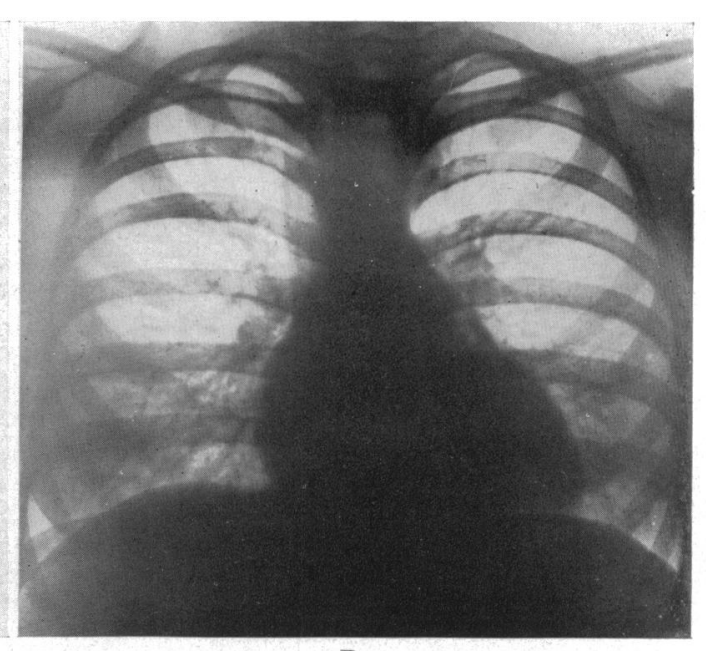

B

FIG. 20.-Teleradiograms (A) before and (B) one year after operation, showing a little increase in the size of the heart: from Case 3, where the result was extremely good. The improvement in the lung markings is somewhat obscured by the breast shadows.

at about 98 per cent. Clubbing of the fingers has entirely disappeared and we have no patient where the change in capacity and in colour had been more striking than in her. In spite of this great improvement there is no change in the right ventricular preponderance (Fig. 21).

She was almost certainly an example of Fallot's tetralogy. At operation the stenosis seemed valvular and of the bicuspid type, and the pulmonary artery itself very small and immature; we were anxious lest such a small vessel might be unable to carry a useful increased supply of blood. The progressive improvement suggests that the vessel has been able to increase in size now that the valvular obstruction has been relieved; certainly her progress and the loud, almost roaring systolic murmur support this.

No diastolic murmur has been heard at any time in her or in the others, and there is no reason to think that any of them have developed pulmonary regurgitation.

Case 4 (H109), aged 25, had never been able to get about much and was practically confined to one room, becoming breathless and cyanosed with moving across it. At rest her cyanosis was very slight for so much disability, and the clubbing of the fingers was also slight. She was encouraged to increase her activity but could not do more than a little walking about the ward.

She had the usual systolic murmur in the pulmonary area and a diminished pulmonary second sound. The heart was not enlarged and was a striking example of the sabot-shaped heart with an unusually turned up apex (Fig. 9). On screening the lung fields were very light, and the right ventricle a little enlarged; the first part of the pulmonary artery was rather prominent and dilated on the left side, suggesting some dilatation beyond the valvular (or possibly high infundibular) stenosis. 
At first, the improvement was difficult to assess because of the hemiplegia, which had become apparent the day after operation. The arterial $\mathrm{O}_{2}$ saturation rose from 77 to 89 per cent. She had to remain in hospital for six months and then could walk only the length of the ward but was still improving.

Re-examined 27 months after operation, her colour looks almost normal and does not change with walking as it had before. She is able to walk a quarter of a mile and is then limited by fatigue in her leg rather than dyspnoea. The left leg is weak and spastic with classical signs. The left arm is also spastic and can hardly be used. Rather to our surprise she is certain that her increased activity has made her operation well worth it, even with the great disability of her hemiplegia. The physical signs do not seem significantly changed and there is no diastolic murmur. The lung fields still appear to suffer from a diminished pulmonary blood flow, though less than before. The heart is still small, but a little larger than before operation, c.t.r 46 instead of 43 ; the shape is just the same as before. Her hæmoglobin had not risen again and is 90 per cent.

Case 10 (0153), aged 22. Cyanosis was noticed from birth and although he talked at 3 he did not walk till 9 years. He had squatted before this and continued to do so till he was 16 years old. His cyanosis was very severe and the hæmoglobin 180 per cent, with a red cell count of 9.4 million. The clubbing of the fingers was much less than would be expected for this. There was a great contrast between his severe cyanosis and less severe disability as he managed regular clerical work and could walk two miles slowly on the flat.

There was a fairly rough systolic murmur both at the apex and in the pulmonary area; the pulmonary second sound' was diminished. Screening showed no great increase in size of heart.

Cardiac catheterization suggested a large shunt $(60 \%$ of cardiac output) and less pulmonary stenosis. Angiocardiography showed slow filling of the heart and of the pulmonary arteries without much increase in lung density. The right-sided aortic arch could be seen from 5 seconds onwards, and the appearance supported an over-riding aorta, though the general slow filling of the heart was more like our picture of valvular stenosis with patent foramen ovale, which would not fit in with the size of the heart or other features.

Valvulotomy was performed on May 23, 1949. Six months after operation he was greatly improved as regards his colour though there was still some cyanosis at rest. His capacity for exertion had been fair before but he found now that he did his work and his two mile walk to and from it much more easily. Going upstairs was also less of an effort.

A year after operation, his improvement is maintained. The hæmoglobin has remained down at 118 per cent instead of the previous 180 per cent. There is no significant change in the size of the heart (Table VII) and the physical signs can not with certainty be said to have changed as the systolic murmur had been rough before operation. It is disappointing that $\mathrm{T} I$, which had always been small, became more deeply inverted after operation, and this has continued. $\mathrm{T}$ inversion has also appeared in V6, though it was less in V3 to V5. Transient changes somewhat of this type have been seen in many patients, but we have seen no other where permanent changes in the standard leads have persisted, and cannot exclude a small infarction.

This fall in the hæmoglobin is a great advantage, as high-grade polycythæmia is an important factor in causing thrombosis, and we thought cerebral thrombosis a considerable risk in this patient. Venesection while waiting for operation lowered his hæmoglobin but it quickly rose to the same level. This advantage is shared, to a smaller extent, by many other patients.

The remaining cases are all improved, greatly improved in 6 of the 8 , but operation is too recent for more final assessment.

\section{Electrocardiographic Changes after Operation}

Certain changes-a cove-shaped S-T with subsequent $T$ inversion in leads $I$ and several chest leads-have been observed progressing and regressing in most cases where section of the right ventricle has been performed; they will be discussed in the paper that follows on infundibular resection (Brock and Campbell, 1950). These changes are probably caused by the muscle section at operation and do not appear to be of lasting importance.

Even in two of the most successful cases there has so far been no diminution of the right ventricular preponderance (Fig. 16 and 21).

\section{The Influence of Age on the Mortality and on the Chances of Success}

The mortality of valvulotomy for pure pulmonary stenosis is at present considerably higher than for valvular stenosis in Fallot's tetralogy. Apart from this difference, the influence of age on the results is similar in the two groups, and the figures have, therefore, been combined. 


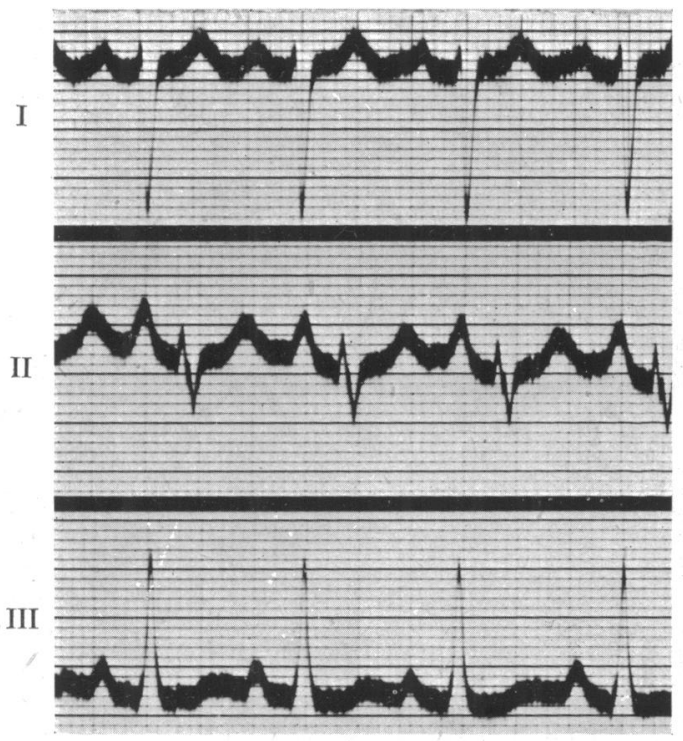

A

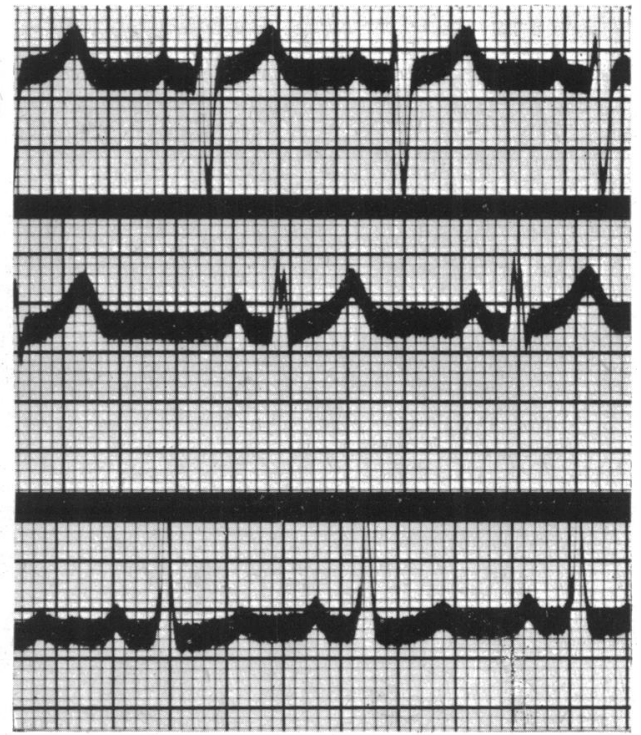

B

FIG 21.-Electrocardiograms from Case 3 with Fallot's tetralogy and valvular stenosis, after most successful operation for valvulotomy, showing no significant change in right ventricular preponderance (confirmed by chest leads). (A) Before operation, (B) 20 months after operation.

As might be expected, the operation is much more dangerous in those over 20 . In those under 10 , there are 9 very good results against 2 deaths: but in those over 20, there are only 2 very good results against 6 deaths, those with only moderate improvement being excluded. The proportion of good results to deaths is 14 times higher in those under 10 than in those over 20 years of age.

Age has a similar effect on the mortality after a systemic-pulmonary anastomosis, and the following are comparable figures for our first 100 cases. Under 10, there were 39 very good results against 7 deaths; but in those over 20, there were only 2 good results against 3 deaths (or in those over 15, 9 good results against 4 deaths). The proportion of good results to deaths is 13 times higher in those under 10 than in those over 20; and this ratio is still over 8 if the range is lowered to those over 15 (instead of over 20) years of age.

This provides another argument in favour of operation at a relatively early age before the changes in the heart have progressed too far.

\section{SUMMARY}

The clinical picture of pure pulmonary stenosis-valvular stenosis with a closed interventricular septum-has been described shortly. Depending on its severity and on whether the foramen ovale is sealed or potentially patent, it can present in very different forms: the disability may be slight or extreme; the patient may be acyanotic or cyanotic, and the cyanosis may date from childhood or may only develop in early adult life; the heart may be only slightly or very greatly enlarged; and the electrocardiogram may show slight or gross signs of right ventricular preponderance.

When the foramen ovale is sealed, there is no alternative route for the blood and the extra work in trying to overcome the obstruction causes hypertrophy of the right ventricle. When the foramen ovale is patent, the back pressure effect is mitigated for a time by the shunting of blood from the right to the left atrium; the price paid is, of course, venous-arterial mixing and cyanosis. In both groups the greatest danger is right-sided heart failure or less often sudden death, sometimes preceded by attacks of unconsciousness. 
In Fallot's tetralogy the stenosis is generally infundibular but often valvular. The differential diagnosis of pure pulmonary stenosis and of Fallot's tetralogy with infundibular stenosis or with valvular stenosis has been discussed.

A short description is given of the technical details of pulmonary valvulotomy. Thirty-three patients have been submitted to this operation, 18 of these with pure pulmonary stenosis, and 15 with valvular stenosis as part of Fallot's tetralogy. The first patients chosen for operation were gravely ill with large hearts and often with congestive failure, and in these circumstances the operative mortality is high. Later operations have included several on younger patients with smaller hearts, where the condition had not progressed so far, and the risks here are very much less.

Details of the 10 deaths have been given, most of these being in older patients with pure pulmonary stenosis.

The results in the 23 survivors are good and all have been improved. With 5 we cannot say more than this as the improvement is much less than we hoped for, but in the remainder it is striking and of the same degree that we have come to expect after a successful Blalock-Taussig operation. No patient has developed a pulmonary diastolic murmur or any other evidence of pulmonary regurgitation.

The first five patients have been followed for from 12 to 27 months and are reported in more detail; they suggest that our early assessment of the good results in the others will be borne out, as none of them has lost ground and one, at least, continued to improve for several months.

The success of the operation is more difficult to judge in the first two or three weeks, but the degree of improvement noted on leaving hospital is generally borne out by the later follow-up.

There can be no doubt that pulmonary valvulotomy is the right treatment for pure pulmonary stenosis. It is an effective treatment for valvular stenosis in Fallot's tetralogy, and the final decision of the best procedure will come from a longer follow-up of these and other cases.

Some temporary changes in the electrocardiogram, suggesting muscle injury, are seen during the few weeks following operation; these disappear in the standard but not always in the chest leads. In some of the successful cases where the heart was relatively small, there has been a little increase in its size after operation.

The symptoms, the size of the heart, the pressure in the right ventricle, and the special electrocardiographic pattern must all be taken into account in deciding the need for and the time of operation. In patients over 20 the risks of operation are much greater and the chance of very good results much less than in those under 10 years of age, so operation should not be too long delayed.

We should like to thank Dr. Hills for the angiocardiograms, Dr. Reynolds and Mr. Muir for taking so many electrocardiograms during and after operation; also Dr. Holling, Dr. Zak, and Dr. Deuchar for the results of the catheterization in many of these cases, and Dr. Paul Wood for the same results in Cases 9 and 23, who were admitted to the National Heart Hospital for investigation. Cases 19, 31 , and 33 were investigated by Dr. Paul Wood at the Brompton Hospital and were operated on there. Case 27 was investigated by Professor McMichael of the Postgraduate Hospital, Hammersmith, and was operated on at the Brompton Hospital.

The special instruments for pulmonary valvulotomy are supplied in a graded set and have been made by $\mathrm{Mr}$. R. Schranz of the Genito-Urinary Manufacturing Co. Ltd. We wish to acknowledge our indebtedness to him for his unstinted enthusiasm and co-operation in addition to his high technical ability and skill.

\section{REFERENCES}

Allanby, K. D., and Campbell, M. (1949). Guy's Hosp. Rep., 98, 18.

Brock, R. C. (1948). Brit. med. J., 1, 1121.

- (1949). Ibid., 22, 399.

, and Campbell, M. (1950). Brit. Heart J., 12, 403.

Campbell, M., and Hills, T. H. (1950). Ibid., 12, 65 .

Dow, J. W., Levine, H. D., Elkin, M., Haynes, F. W., Hellens, H. K., Whittenberg, J. W., Ferris, B.G., Goodale, W. T., Harvey, W. P., Eppinger, E. C., and Dexter, L. (1950). Circulation, 1, 267.

Selzer, A., Carnes, W. H., Noble, C. A., Higgins, W. H., and Holmes, R. O. (1949). Amer. J. Med., 6, 3. 